\title{
Forum Genetic History II
}

In Heft 3 (2018) hat NTM im Rahmen der Rubrik „Forum“ die Debatte um ancient DNA (aDNA) aufgegriffen - und damit die Frage, ob und inwiefern neue naturwissenschaftliche Methoden wie die Analyse von aDNA auch neue Einsichten und Herausforderungen für die geschichtswissenschaftliche Forschung mit sich bringen, und ob und wann sie für diese eher irrelevant oder gar kontraproduktiv sind. Die Redaktion hat in dem genannten Heft mit Artikeln von Wolfgang Haak und Stephan Schiffels, Mischa Meier und Steffen Patzold, Jan Keupp, Jörg Feuchter und Philipp von Rummel, die Gerrit Jasper Schenk zusammengestellt und eingeleitet hat, die Sicht von Vertretern des Max-Planck-Instituts für Menschheitsgeschichte (MPI$\mathrm{SHH}$, Jena) sowie von Historikern und Archäologen vorgestellt. Die Artikel dieses ersten Forums setzten sich mehrheitlich mit Fragen von Migration und Bevölkerung zwischen Vorgeschichte und Mittelalter auseinander und spiegeln damit vor allem auch die bisherige öffentliche Rezeption der Debatte wider.

Um diesen - unserer Meinung nach zu engen - Fokus auszuweiten, hatte die NTM-Redaktion zugleich zu Beitragseinreichungen aufgerufen, die die aDNA-Debatte in ihrer besonderen Relevanz für die Fächer der Wissenschafts-, Technik- und Medizingeschichte erörtern sollten. Denn erstens liegen in diesen Feldern bereits kritische Auseinandersetzungen zur Geschichte von Populationsgenetik und der Herausbildung von aDNA als Forschungsmethode vor. Zweitens betrifft die Debatte eine bekannte Kernfrage unserer Fächer, nämlich diejenige nach der Rolle naturwissenschaftlicher Ansätze und Methoden bei der Arbeit des/der Historiker/in, und allgemein innerhalb einer geistes- und sozialwissenschaftlichen Wissenschafts- und Technikforschung.

Das aus diesem Aufruf resultierende aktuelle „Forum“ erweitert die Perspektive in diesem Sinne. So weist Veronika Lipphardt auf diverse methodische Fallstricke und problematische Engführungen hin, wenn etwa aDNA-Daten mit DNA-Daten heutiger Populationen korreliert werden, wenn mit vereinfachenden, ahistorischen Gruppenbezeichnungen operiert oder von biologischen Daten unmittelbar auf kulturelle Verhältnisse geschlossen wird. Elsbeth Bösl bettet die Debatte in den größeren Kontext der kooperativen wie konkurrierenden Wissensgenerierung durch 
Vertreter/innen der Naturwissenschaften, der Archäologien und der Geschichtswissenschaften ein und historisiert die von der aDNA-Forschung bereitgestellten Deutungen, die im Zuge der Weiterentwicklung von Untersuchungstechniken und im Licht neuer Funde überarbeitet werden mussten. Für die Klimageschichte skizziert Martin Bauch die Gratwanderung zwischen historischer Klimatologie, geowissenschaftlicher Eisbohrkernforschung und Geschichtswissenschaft und diskutiert an einem Beispiel die oft von den betreffenden Forscher/innen nicht wahrgenommenen - Grenzen der naturwissenschaftlich gewonnenen Proxydaten. Matthis Krischel stellt abschließend die retrospektive Diagnose vor: Die Medizingeschichte diskutiert bereits seit Jahrzehnten, wie problematisch es ist, aktuelles medizinisches Wissen auf historische Krankheitsfälle anzuwenden, wenn das damalige medizinische Wissen sowie dessen kulturelle Einbettung demgegenüber zweitrangig werden.

Die NTM-Redaktion 


\section{Kommentare}

\section{Über den allzu sorglosen Umgang mit population labels und sampling schemes}

Veronika Lipphardt

\section{Eine problematische Engführung}

Das NTM-Forum zu Genetic History ist ein wichtiger Schritt auf dem Weg zu einer interdisziplinären Verständigung über die Grenzen und Chancen humanpopulationsgenetischer Forschung und ihrer Anwendungsmöglichkeiten. Unter letzteren wirkt die Genetic History wie ein harmloser, bildungsaffiner, feuilletontauglicher Publikumsliebling, der viele Bedürfnisse befriedigt und scheinbar niemanden vor den Kopf stößt. Andere Anwendungen haben hingegen bereits Alarmreaktionen hervorgerufen: Populationsgenetische Verfahren kommen mittlerweile in staatlichen Handlungsbereichen zum Einsatz, etwa in der Strafverfolgung und im Grenzschutz, und sind heftig umstritten. Im biomedizinischen Bereich sorgen sie schon seit einiger Zeit für lebhafte Debatten über problematische population labels und deren potentiell diskriminierende, rassifizierende und reifizierende Effekte. ${ }^{1}$ Lediglich das kommerzielle ancestry testing, auch genetic genealogy genannt, pflegt ein ähnlich harmloses Image, wobei es mittlerweile vielseitige Kritik aus allen möglichen Wissenschaftszweigen (inklusive der Genetik) und der Öffentlichkeit hagelt.

In all diesen Anwendungsbereichen der Populationsgenetik finden sich stark übertriebene Erkenntnisversprechen. Wie ein roter Faden durchzieht die kritischen Kommentare die Zurückweisung dieser großen Versprechen als überzogen. Doch weil sie sich gut vermarkten lassen, weil es eine ungebrochene Nachfrage nach großen Erzählungen von Herkunft und Identität gibt, sind sie publikumswirksam und prägen das Bild der Populationsgenetik in der Öffentlichkeit. Die differenzierteren, nüchternen und zum Teil sehr kritischen Stimmen innerhalb dieses Forschungsfeldes, die keine unangemessen hohen Erwartungen beim Publikum wecken wollen, bleiben eher ungehört. Wenig bekannt ist, dass schon der Populationsbegriff in der sogenannten molecular anthropology nicht definiert ist (Jobling et al. 2014; Stoneking 2016; Wapples \& Gagiotti 2006), und dass Populationen nicht als „Container" oder gut abgrenzbare Entitäten zu verstehen sind.

Dieser Kommentar betont, dass die übergroßen Erkenntnisversprechen der Genetic History keine harmlose Angelegenheit sind. Zum einen greifen ihre Vertreter*innen oftmals historische Narrative über soziale Gruppen 
oder politische Entitäten auf, die seit dem späten 19. Jahrhundert und bis weit ins 20. Jahrhundert hinein konflikthaft aufgeladen waren, selbst wenn es um prähistorische Geschehnisse ging. Zum anderen begnügt sich aDNAForschung selten mit Forschungsfragen, die sich ausschließlich um Menschen in der fernen Vergangenheit drehen. Was man alten Skeletten an genetischer Information entlocken kann, wird in den Studien fast immer mit den DNA-Daten heute lebender Menschen abgeglichen. Die Genetic History ist deshalb mit der Populationsgenetik heutiger Populationen eng verflochten, deren Berührungsflächen mit heutigen Identitätsdiskursen nicht zu übersehen sind. Die Zuordnung von DNA-Daten lebender Menschen zu Gruppenbezeichnungen ist alles andere als trivial oder selbsterklärend und kann Folgen für die betroffenen Individuen haben. Kritische Perspektiven, die vor allem für den biomedizinischen Bereich sowie für das ancestry testing bereits entwickelt wurden, sollten also auch für die Genetic History zum Tragen kommen.

In der Genetic History und auch in der NTM-Forumsdebatte sind diese kritischen Arbeiten bisher noch nicht oder nur unzureichend rezipiert worden. Das mag daran liegen, dass Sozialwissenschaftler*innen nicht als relevante Diskussionspartner*innen für Genetic History betrachtet werden weder von den Genetikern des MPI für Menschheitsgeschichte in Jena, die den Hauptbeitrag der NTM-Forumsdebatte verfasst haben, noch von den kommentierenden Historikern und Archäologen. Dabei schreiben Geistesund Sozialwissenschaftler*innen (z. B. aus den Science and Technology Studies, aus der Philosophie und der Kulturanthropologie) schon seit Jahren über Populationsgenetik und ihre verschiedenen Anwendungen und warnen vor den gesellschaftlichen Folgen essentialistischer Gruppenbezeichnungen. ${ }^{2}$ Auch Neuzeithistoriker*innen werden offenbar nicht als relevante Gesprächspartner*innen betrachtet, vielleicht weil das MPI in Jena vorwiegend prähistorische und mittelalterliche Themen bearbeitet. Aber sobald zwischen aDNA-Daten und den DNA-Daten heutiger Populationen Beziehungen hergestellt werden, ist die gesamte Geschichtsschreibung der vergangenen Jahrhunderte aufgerufen.

Ich halte diese Engführung der interdisziplinären Debatte zur Genetic History für einen Fehler. Geschichtsnarrationen können sehr große gesellschaftliche und politische Wirksamkeit entfalten, vor allem, wenn sie mit identitätsstiftenden Bezeichnungen für imagined communities (Anderson) aufwarten. Die Resonanzen zwischen konflikthaft aufgeladenen Identitätsdiskursen und der Genetic History sind nicht zu übersehen, selbst wenn manche der beteiligten Genetiker*innen keine politischen Aussagen zu treffen beabsichtigen.

Im Forumsbeitrag von Wolfgang Haak und Stephan Schiffels im September 2018 („Möglichkeiten und Grenzen molekulargenetischer Untersu- 
chungen in den Geschichtswissenschaften“) heißt es im Hinblick auf Gruppenbezeichnungen: „Eine Vereinfachung der Sachlage dient hier als Mittel zum Zweck und muss zur Beschreibung der Allgemeinbefunde zunächst in Kauf genommen werden“ (Haak \& Schiffels 2018: 319); zum Beispiel, so die Autoren, Bezeichnungen wie „Kelten“, „Frühbauern“ oder „Schnurbandkeramiker“. Aber was heißt „zunächst“ - wann findet die notwendige Differenzierungsarbeit, die in den geisteswissenschaftlichen NTM-Forumskommentaren vollkommen zu Recht eingefordert wird, denn statt? Selbst wenn simplifizierende Bezeichnungen für prähistorische Gemeinschaften wenig problematisch erscheinen mögen, so sollten zumindest simplifizierende Gruppenbenennungen für heute lebende Menschen keinesfalls in Kauf genommen oder unkommentiert verwendet werden. Zumal - so meine Hauptthese in diesem Kommentar - sie für wissenschaftliche Zwecke zu ungenau sind und daher wissenschaftlichen Qualitätsstandards nicht genügen.

\section{Sampling schemes und Gruppenbezeichnungen}

Haak und Schiffels, die beiden Genetiker aus dem MPI für Menschheitsgeschichte in Jena, schreiben in ihrem NTM-Forumsbeitrag nicht nur über „Frühbauern“ und „Kelten“, sondern auch über die genetische Variabilität zwischen „Spaniern“ und „Deutschen“, über Individuen aus den „Regionalgruppen" Rheinhessen und Schwarzwald, und, in ihrer zweiten Fallstudie, von „heutigen Holländern“ und „heutigen Engländern“ (Haak \& Schiffels 2018: 318f.). Damit scheint glasklar zu sein, was gemeint ist - eine Erläuterung, wie diese Bezeichnungen verwendet werden, sucht man vergeblich. Die Autoren halten es nicht mehr für erklärungsbedürftig, wen sie mit „heutigen Holländern“ meinen. Dabei geht es ja immerhin um die Kriterien, anhand derer entschieden wurde, wer für diese Studien als „heutiger Holländer" (bzw. „heutige Holländerin“) in die Datenbank aufgenommen wird und wer nicht. Solche Samplingentscheidungen müssen in wissenschaftlichen Studien offengelegt werden; sie sind ein wichtiger Anhaltspunkt für die Beurteilung der Aussagekraft und Reichweite der erzielten Ergebnisse.

In politikwissenschaftlichen und behördlich-administrativen Kontexten wie auch in weiten Teilen des politischen Diskurses ist mit Nationalbezeichnungen wie „Holländer*innen“, „Spanier*innen“, „Deutsche“, wenn nicht anders angegeben, selbstverständlich die Staatsangehörigkeit angesprochen. Anders bei Haak und Schiffels: Als „heutige Holländer“ gelten ihnen - ohne, dass dies diskutiert oder auch nur erläutert wird - nicht etwa 
alle Personen, die die niederländische Staatsangehörigkeit haben oder in den Niederlanden geboren wurden, sondern Menschen, deren Vorfahren über mehrere Generationen hinweg mit großer Wahrscheinlichkeit in den Niederlanden geboren wurden. Um diese Herkunftseingrenzung für mögliche Studienteilnehmer*innen zu eruieren, deren DNA dann mit einem label wie etwa „Dutch“ in einer Datenbank gespeichert werden kann, verwenden Forschungsprojekte zum Beispiel die four-grandparents-rule: Wenn alle vier Großelternteile innerhalb eines bestimmten geografischen Gebietes geboren wurden (z.B. in „East England“, siehe Schiffels et al. 2016), qualifiziert sich der Enkel für die Aufnahme in die entsprechende Referenzpopulation. Personen, deren vier Großeltern nicht derart überschaubaren geografischen Verhältnissen entstammen oder über keine belastbaren Informationen verfügen, können nicht mit einbezogen werden. Zahlreiche Menschen werden somit aus dem jeweiligen Kollektiv ausgeschlossen, egal, wie sehr sie sich selbst als dem Kollektiv zugehörig betrachten - oder von anderen als zugehörig betrachtet werden. Und dabei könnte es sich in manchen Fällen durchaus um die überwiegende Mehrheit eines solchen Kollektivs handeln.

In einer viel zitierten Studie von John Novembre und seinen Kolleg*innen (2008), die die Bevölkerungsstruktur Europas genetisch darzustellen beabsichtigte, wird dieses Ausschließen explizit benannt:

„We applied various stringency criteria to avoid sampling individuals from outside of Europe, to create more even sample sizes across Europe, to exclude individuals with grandparental ancestry from more than [one] location, and to avoid potential complications of SNPs in high linkage disequilibrium." (Novembre et al. 2008: 98)

Dadurch wurde die Zahl der berücksichtigten Individuen um mehr als die Hälfte, von 3192 auf 1387, reduziert. „These numbers“, schreiben die Autor*innen, „exclude individuals who reported mixed grandparental ancestry, who are typically assigned to locations between those expected from their grandparental origins [...]." (Novembre et al. 2008: 99)

Aus Perspektive der Genetik wirken diese Ausschlusskriterien unproblematisch: Geografisch fokussiert man auf Europa, da man die Bevölkerungsstruktur Europas darstellen möchte (wobei man allerdings nur die Struktur der am wenigsten mobilen Bevölkerungsanteile Europas erfasst). Aber wo beginnt, wo endet Europa? Welche Grenze zu Asien wird dabei angenommen? Was ist mit der Mittelmeerregion? Und was bedeutet es, Individuen "from outside of Europe“ oder mit "mixed ancestry“ (Novembre et al. 2008: 98f.) aus einem Datensatz auszuschließen, der die Bevölkerungsstruktur Europas darstellen soll? Wie geht man dabei praktisch vor? Wird erst im Nachhinein jedes DNA-Datenset, dessen genetische Daten auf nichteuropäische Vorfahren hindeuten, aussortiert? Oder geschieht dies bereits bei der Rekrutierung potentieller Proband*innen? Woran erkennen 
Forscher*innen, ob etwa einer der Vorfahren einer teilnahmewilligen britischen Staatsbürgerin aus Südafrika, China, Irak, Nordafrika oder Südamerika, aber jedenfalls nicht aus Europa stammt? Zumal, wenn die Person diese Informationen selbst nicht liefert oder nicht liefern kann? Spielt das Aussehen eines potentiellen Probanden hierbei eine Rolle?

Erst vor kurzem hat der Genetiker David Reich eine hitzige Debatte um den Begriff „race“ ausgelöst (Reich 2018). Mit seiner unpräzisen Ausdrucksweise hat Reich in Kauf genommen, dass der Begriff „race“ in seinem Text missverstanden wurde: Nicht, wie in den USA üblich, als Zensuskategorie, die eine soziale Selbstverortung ermöglicht, sondern als biologischer Begriff, der lediglich auf die Herkunftsregion der Vorfahren verweist (Lipphardt et al. 2018). Zwar gibt es Zusammenhänge zwischen diesen verschiedenen Formen der Zuordnung, und auch zwischen ihnen und äußerlichen Merkmalen, aber diese Zusammenhänge sind komplex; es gilt, sie in all ihrer Komplexität aufzuzeigen, anstatt sie implizit gleichzusetzen. In der Novembre-Studie scheint es vordergründig nur um Geografie zu gehen; auf der praktischen Ebene des Samplings - wer wird in den Datensatz aufgenommen, wer wird ausgeschlossen - könnten solche impliziten Gleichsetzungsprozesse eine Rolle gespielt haben.

In ihrem Forumsbeitrag beziehen sich Haak und Schiffels auf eine Studie, in der eine ähnliche Vorgehensweise gewählt wurde; nur waren in diesem Fall die geografischen Ausschlusskriterien noch viel enger gefasst, weil es um die Bevölkerungsstruktur Großbritanniens ging (Leslie 2015). Zu dieser Studie konnten nur diejenigen DNA beitragen, bei denen die Geburtsorte der Großeltern nicht weiter als $80 \mathrm{~km}$ voneinander entfernt lagen. Erfasst werden unter solchen Samplingbedingungen lediglich Angehörige „alteingesessener", meist ländlicher Familien, die kaum Mobilität erfahren, erduldet oder praktiziert haben. Im vorliegenden Fall schließt das Sampling also nicht nur sämtliche Brit*innen aus, die Vorfahren aus anderen Ländern haben, selbst wenn die Großeltern schon seit früher Kindheit als britische Staatsbürger*innen in Großbritannien lebten. Es schließt auch viele Brit*innen aus, deren Vorfahren alle aus Großbritannien stammen, die aber dieses enge Kriterium nicht erfüllen: Man denke an zahlreiche Berufsgruppen, deren Aktionsradius deutlich größer war als $80 \mathrm{~km}$, an herumreisende Auszubildende oder Studierende, an die Industrialisierung, die Landflucht und andere Mobilitätsmuster, von erzwungener Mobilität ganz zu schweigen. Hingegen geht diese genetische Studie ausschließlich von lokal und gesellschaftlich festgelegten Verhältnissen aus; man heiratet im Dorf oder im Nachbardorf, wo die Familien schon seit Jahrhunderten ansässig sind.

Wenn also Haak und Schiffels wie selbstverständlich auf „heutige Holländer“, „heutige Engländer“ (Haak \& Schiffels 2018: 318) oder „modern samples“ aus „East England“ (Schiffels et al. 2016: 3) Bezug nehmen, fehlen wich- 
tige Informationen, die präzisieren würden, was damit gemeint ist; zumal, wenn dann auch noch prozentuale Angaben über angebliche historische Verwandtschaften auftauchen: „[...] 38 \% der Vorfahren heutiger Engländer [waren] angelsächsische Migranten [...]“ (Haak \& Schiffels 2018: 318). Es macht einen Unterschied, ob hier mit den „heutigen Engländern“ britische Staatsangehörige gemeint sind, oder Personen, deren Großeltern britische Staatsangehörige waren, oder Personen, deren Großeltern innerhalb eines eng umgrenzten Gebietes zur Welt kamen.

In vielen populationsgenetischen Studien sowie im ancestry testing findet eine implizite Verschiebung statt: Wenn nicht anders angegeben, meinen die Autor*innen mit nationalen Bezeichnungen wie selbstverständlich die eng definierte Vorfahren-Herkunft und setzen damit voraus, dass dies allgemeiner Konsens sei und keinerlei Erläuterung bedürfe. Damit entstehen zahlreiche Missverständnisse in der Rezeption der Ergebnisse; Autor*innen genetischer Studien, die diese Missverständnisse durch unterlassene Präzisierung in Kauf nehmen, tragen dadurch zu heutigen Identitätsdiskursen bei.

Die Autoren bleiben wichtige Informationen schuldig, etwa, ob es sich bei diesen Bezeichnungen um self-reported ethnicity oder self-reported ancestry handelt, die als proxy verwendet werden, oder ob sie für Definitionen bestimmter Gruppen stehen, die mit den Selbstäußerungen der Proband*innen nicht unbedingt übereinstimmen. Diese Definitionen müssten sodann explizit gemacht werden, ebenso wie die Auswahlkriterien, die aus ihnen abgeleitet werden, denn sonst sind die erzielten Ergebnisse nicht überprüfbar. Ethnizität ist zudem nicht einfach ein Synonym für „biologische Einheit" oder „Fortpflanzungsgemeinschaft“; es ist vielmehr ein hochentwickelter Begriff aus den Sozialwissenschaften, hinter dessen theoretischem Anspruch interdisziplinäre Debatten über Populationsgenetik nicht zurückbleiben sollten. In Anlehnung an diesen Forschungsstand sieht etwa der US-amerikanische Zensus für die Kategorie race/ethnicity die Möglichkeit der Mehrfachzuordnung vor, wie auch die Wahlmöglichkeit „other“, wenn die vorgeschlagenen Optionen nicht in Frage kommen.

Wenn man aber nichts erfährt über die Auswahl- und Zuordnungskriterien der Proband*innen (Selbstzuschreibung? Staatsangehörigkeit? Wohnort? Geburtsort? Wohn- oder Geburtsort der vier Großeltern oder der Vorfahren? Grabbeigabe? „Ansprache“?), wenn die Autoren präzise Informationen zum Sampling der verwendeten Daten schuldig bleiben, können Studienergebnisse nicht angemessen eingeordnet und diskutiert werden. Weil die Autoren die notwendige Begriffsarbeit nicht leisten, geraten ihre Aussagen zu groß, bieten Anschluss an problematische Identitätsdiskurse und leisten Fehlinterpretationen Vorschub. 
Aus der Perspektive der Genetic History macht es freilich Sinn, eng umrissene Abstammungsverhältnisse zu bevorzugen: Je mehr Menschen per Definition aus einem zu untersuchenden Kollektiv ausgeschlossen werden können, umso signifikanter können idealerweise die Forschungsergebnisse ausfallen, da man ja Personen, deren genetische Profile vermutlich nicht in das definierte Kollektiv passen würden, von vornherein ausschließen kann. Ein solches Vorgehen ist nicht per se problematisch; aber die erhobenen Daten können dann eben keinerlei nationale oder ethnische Bevölkerungsgruppe repräsentieren, weder eine heutige noch eine historische, sondern allenfalls eine sehr spezifische soziokulturelle Gruppe. Um das Erkenntnispotential nicht zu übertreiben, um keine Fehlinterpretationen zu provozieren, muss man genau erläutern, für welche historische Situation oder Gruppe die erhobenen Daten repräsentativ sein können und für welche nicht. Dieser Punkt wird von vielen Autor*innen, Journals und den Medien ignoriert. Hierbei so korrekt und präzise wie möglich (also: wissenschaftlich) zu formulieren, würde vermutlich vielen Studien ihren selling point verderben.

Dass Haak und Schiffels solche Vereinfachungen für statthaft halten, liegt daran, dass soziale Kategorisierungen in ihrer Disziplin als nachgeordnet gelten. Nicht nur „nachgeordnet“ im Sinne von „weniger wichtig“, sondern im Hinblick darauf, welche Daten als die grundlegenden, verlässlichen Daten bei der Charakterisierung einer Bevölkerungsgruppe angesehen werden und welche nicht. Soziale Kategorisierungen sind aus Sicht der Genetic History der genetischen „Feststellung einer quantifizierbaren, biologischen Einheit“ (Haak \& Schiffels 2018: 320) nachgeordnet; mit letzterer ist folgendes gemeint: eine „Gruppe mit gemeinsamem genetischen Profil, welche die Fortpflanzungsgemeinschaft widerspiegelt“ (ebd.). Laut Haak und Schiffels bieten kulturelle Bezeichnungen lediglich eine „Kontextualisierung und Kategorisierung derselben “ (ebd.) - also „der biologischen Einheit“. Die Benennung der biologischen Einheit kann „anhand charakteristischer kultureller, geografischer oder zeitlicher Merkmale“ erfolgen; sie verwendet „in erster Linie Konventionen“, ist „flexibel“, und daher zwar nicht „formal korrekt“ im Sinne der Naturwissenschaften, aber „in Kürze informativer und unmissverständlicher" als „rein sachliche Lösungen“ (ebd.).

Anders gesagt: Wenn man den eigentlichen Forschungsgegenstand, die „biologische Einheit“, mit naturwissenschaftlichen Methoden quantifiziert und charakterisiert habe, dann könne man anschließend konventionelle Kulturbezeichnungen als recht verlässliche Denominatoren verwenden - denn dass sie unzweideutig, klar und eng mit der biologischen Einheit und deren gemeinsamem genetischen Profil verknüpft sind, wird stets vorausgesetzt. Allerdings wäre genau das das Explanandum, denn der Zusammenhang zwischen Fortpflanzungsgemeinschaft und selbstgewählter oder fremdbestimmter Gruppenbezeichnung kann nicht einfach als gegeben vo- 
rausgesetzt werden; er mag in manchen Fällen eng sein, in anderen ist er es nicht. Und nur, wenn es einen engen, schlichten Zusammenhang gibt, dann taugt der Fall für eine Modellierung; komplexere Fälle lassen sich hingegen kaum in ein testbares Modell überführen.

Komplexere Verhältnisse dürfte es z. B. überall dort geben, wo Familienorganisation, Heiratsstrategien und Mobilitätsmuster nicht den heutigen geordneten bürgerlichen Verhältnissen oder der oben erwähnten Dorfheiratsregel entsprechen. Solche komplexen Situationen waren von der Frühen Neuzeit bis ins 20. Jahrhundert auch in Europa eher die Regel denn die Ausnahme und resultierten aus unterschiedlichsten Macht- und Produktionspraktiken: Versklavungen, Vergewaltigungen, freiwillige und unfreiwillige regelmäßige Sexualkontakte, ausbeuterische Dienstverhältnisse, Menschenhandel, Reproduktionspolitik etwa für Kinderarbeit in der Landwirtschaft, Zwangsumsiedlungen, Deportationen, Vertreibungen und vieles mehr bestimmten die vielfältigen Zugehörigkeiten zahlreicher Individuen (siehe z.B. Wawruschka 2017: 142f.). Ob vor diesem Hintergrund ein paar Skelette eine Aussage über die Zugehörigkeit zu einer soziokulturellen Gruppe gestatten, als deren Angehörige sie von den Genetikern ,angesprochen" (Haak \& Schiffels 2018: 318) werden, ist fraglich.

Insofern überzeugt sogar eine relativ bescheiden formulierte Aussage des Beitrags der beiden Jenaer Genetiker nicht: „Mit Hilfe seltener genetischer Varianten konnte in dieser Studie eindeutig gezeigt werden, dass sich die Herkunft früh- und mittelangelsächsischer Individuen klar von der Herkunft solcher aus der späten Eisenzeit unterscheidet (ebd.)“ - präziser müsste es heißen: „...dass sich das genetische Profil der als früh- und mittelangelsächsisch eingeordneten Individuen klar unterscheidet von dem genetischen Profil solcher, die der späten Eisenzeit zugeordnet werden, was auf unterschiedliche geografische Herkünfte hinweist". Bei diesem beachtlichen Ergebnis hätte man es belassen können; aber historische Deutungen werden eben nur dann publikumswirksam, wenn sie mit aktuellen Identitätsdiskursen (in diesem Fall: „heutige Holländer“, „heutige Engländer“) verbunden werden.

Übrigens benennen Haak und Schiffels als einen wesentlichen Verdienst ihrer aDNA-Studie, dass sie „aus modernen Daten abgeleitete Schätzungen von zehn bis 90 \% deutlich eingeschränkt" hätte (ebd.). In ihrer Originalpublikation von 2016 hieß es jedoch, bisherige Studien hätten "most likely 10 to $40 \%$ “ (Schiffels et al. 2016: 2) geschätzt. Ihre eigene Arbeit habe hingegen ergeben, "that on average 25-40\% of the ancestry of modern Britons was contributed by Anglo-Saxon immigrants, with the higher number in East England closer to the immigrant source“ (ebd.: 3). Man kann darüber streiten, ob eine Eingrenzung von 10-40 \% auf 25-40\% ein großer Erkenntnisfortschritt und ob „im Mittel 38 \%“ (Haak \& Schiffels 2018: 318) ein sinnvol- 
ler Ausdruck dieser Spanne ist; aber das Ergebnis trifft jedenfalls nicht auf „modern Britons“ zu, sondern allenfalls auf Menschen, deren Vorfahren mit großer Wahrscheinlichkeit sämtlich aus Großbritannien stammten.

Manche Narrative zirkulieren widerstandslos und einfach, weil sie einen gesellschaftlichen Bedarf decken; für andere besteht keine Nachfrage, sie geraten gar nicht erst in die Umlaufbahn zwischen Labor und Öffentlichkeit. Wie die bisherigen Kommentare des Forums für den Hauptbeitrag bereits überzeugend argumentiert haben, dürfte die Genetic History ihr größtes Wirkungspotential wohl nicht bei der Beantwortung historischer Fragen haben. Stärkere Wirkung wird sie voraussichtlich im Rahmen heutiger Geschichtspolitiken und Identitätsdiskurse haben, also dort, wo es eine klare Nachfrage nach Bestätigung bestimmter Narrative gibt; und vielleicht künftig auch in Aus- und Abgrenzungsmanövern, die auf biologistische Denkfiguren zurückgreifen. Vielleicht unterschätzen die genetic historians das, was sie sehr knapp „ideologischen Ballast“ (S. 312) nennen: Humangenetik in Verbindung mit Identitätspolitik birgt sehr viel mehr und komplexere Gefahren als nur „ideologischen Missbrauch“ (ebd.). Auf dieses Thema spezialisierte Historiker*innen wären hierfür gute Gesprächspartner*innen. Niemand würde die Vertreter*innen der Genetic History außerdem daran hindern, sich deutlich und öffentlichkeitswirksam gegen Vereinnahmungen und überzogene Erwartungen auszusprechen, oder sich für eine hohe gesellschaftliche Sensibilität und für differenzierende Präzision im Umgang mit Populationsbezeichnungen und Zugehörigkeits- oder Samplingkriterien einzusetzen. Im wissenschaftsinternen Bereich darf man eine solche Sensibilisierung bei Autor*innen, Journals, Rezensent*innen und Gutachter*innen erwarten - sie müsste eigentlich als State of the Art vorausgesetzt werden können.

\section{Anmerkungen}

1 Siehe z. B. Ali Khan 2011; Barbujani, Ghirotto \& Tassi 2013; Hindorff et al. 2018; Lee et al. 2008; Royal et al. 2010; Claw et al. 2018.

2 Siehe z.B. Bliss 2012; Duster 2003; Fullwiley 2008; Lipphardt 2014; Lipphardt 2018; M'charek 2005; Radin and Kowal 2015; Reardon 2005, 2017; Tallbear 2013; Wade et al. 2014; Bliss 2015; Bolnick et al. 2007; Duster 2015; El Haj 2007; Epstein 2007; Fujimura and Rajagopalan 2011; Fujimura, Duster and Rajagopalan 2008; Gannett 2014; Lee, Mountain and Koenig 2001; M'chareck, Schramm, Skinner 2014; Schramm, Skinner and Rottenburg 2012; Wailoo, Nelson and Lee 2012; Sommer 2008, 2015. 


\section{Literatur}

Ali-Khan, Sarah E., Tomasz Krakowski, Rabia Tahir und Abdallah S. Daar 2011. The Use of Race, Ethnicity and Ancestry in Human Genetic Research. HUGO Journal (5): 47-63.

Barbujani, Guido, Silvia Ghirotto und Francesca Tassi 2013. Nine Things to Remember about Human Genome Diversity. Tissue Antigens (82): 155-164.

Bliss, Catherine 2012. Race decoded: The Genomic Fight for Social Justice. Stanford, CA: Stanford University Press.

Bliss, Catherine 2015. Science and Struggle: Emerging Forms of Race and Activism in the Genomic Era. The ANNALS of the American Academy of Political and Social Science (661): 86-108.

Bolnick, Deborah A. et al. 2007. The Science and Business of Genetic Ancestry Testing. Science (318): 399-400.

Claw, Katrina G. et al. 2018. A Framework for Enhancing Ethical Genomic Research with Indigenous Communities. Nature Communications (9): 2957.

Duster, Troy 2003. Backdoor to eugenics. New York: Routledge.

Duster, Troy 2015. A post-genomic Surprise. The Molecular Reinscription of Race in Science, Law and Medicine. British Journal of Sociology (66): 1-27.

El-Haj, Nadja Abu 2007. The Genetic Reinscription of Race. Annual Review of Anthropology (36): 283-300.

Epstein, Steven 2007. Inclusion: The Politics of Difference in Medical Research. Chicago: University of Chicago Press.

Fujimura, Joan H. und Ramya Rajagopalan 2011. Different Differences: The Use of ,genetic ancestry versus Race in Biomedical Human Genetic Research. Social Studies of Science (41): 5-30.

Fujimura, Joan H., Troy Duster und Ramya Rajagopalan 2008. Introduction: Race, Genetics, and Disease: Questions of Evidence, Matters of Consequence. Social Studies of Science (38): 643-656.

Fullwiley, Duana 2008. The Biologistical Construction of Race: ,Admixture‘ Technology and the New Genetic Medicine. Social Studies of Science (38): 695-735.

Gannett, Lisa 2014. Biogeographical Ancestry and Race. Studies in History and Philosophy of Biological and Biomedical Sciences (47): 173-184.

Haak, Wolfgang und Stephan Schiffels 2018. Möglichkeiten und Grenzen molekulargenetischer Untersuchungen in den Geschichtswissenschaften. NTM (26): 310-324.

Hindorff, Lucia et al. 2018. Prioritizing Diversity in Human Genomics Research. Nature Reviews Genetics (19): 175-185.

Jobling, Mark et al. 2014. Human Evolutionary Genetics. 2. Aufl. New York und London: Garland Science.

Lee, Sandra Soo-Jin et al. 2008. The Ethics of Characterizing Difference: Guiding Principles on Using Racial Categories in Human Genetics. Genome Biology (9): 404.

Lee, Sandra Soo-Jin, Joanna Mountain und Barbara A. Koenig 2001. The Meanings of „Race“ in the New Genomics: Implications for Health Disparities Research. Yale Journal of Health, Policy, Law and Ethics (1): 33-75.

Leslie, Stephen et al. 2015. The fine-scale Genetic Structure of the British Population. Nature (519): 309-314.

Lipphardt, Veronika 2018. Vertane Chancen? Die aktuelle politische Debatte um Erweiterte DNA-Analysen in Ermittlungsverfahren. Berichte zur Wissenschaftsgeschichte (41): 279-301.

Lipphardt, Veronika et al. 2018. Lost in Translation. Süddeutsche Zeitung (113): 18.

Lipphardt, Veronika 2014. „Geographical Distribution Patterns of Various Genes“: Genetic Studies of Human Variation after 1945. Studies in History and Philosophy of Biological and Biomedical Sciences (47): 50-61.

M'charek, Amade 2005. The Human Genome Diversity Project: An Ethnography of Scientific Practice. Cambridge: Cambridge University Press. 
M'charek, Amade, Katharina Schramm und David Skinner 2014. Topologies of Race: Doing Territory, Population and Identity in Europe. Science, Technology, E Human Values (39): $468-487$.

Novembre, John et al. 2008. Genes Mirror Geography within Europe. Nature (456): 98-101.

Radin, Joanna und Emma Kowal 2015. Indigenous Blood and Ethical Regimes in the United States and Australia since the 1960s. American Ethnologist (42): 749-765.

Reardon, Jenny 2005. Race to the finish: Identity and Governance in an Age of Genomics. Princeton, NJ: Princeton University Press.

Reich, David 2018. How Genetics Is Changing Our Understanding of ,Race‘. New York Times (CLXVII): SR1.

Royal, Charmaine et al. 2010. Inferring Genetic Ancestry: Opportunities, Challenges, and Implications. The American Journal of Human Genetics (86): 661-673.

Schiffels, Stephan et al. 2016. Iron Age and Anglo-Saxon Genomes from East England reveal British Migration History. Nature Communications (7): 10408.

Schramm, Katharina, David Skinner und Richard Rottenburg 2012. Introduction. Ideas in motion: Making Sense of Identity. In: Katharina Schramm, David Skinner und Richard Rottenburg (Hg.). Identity Politics and the new Genetics: Re/creating Categories of Difference and Belonging. New York und Oxford: Berghahn Books: 1-29.

Sommer, Marianne 2008. History in the Gene: Negotiations between Molecular and Organismal Anthropology. Journal of the History of Biology (41): 473-528.

Sommer, Marianne 2015. Evolutionäre Anthropologie zur Einführung. Hamburg: Junius.

Stoneking, Mark 2017. An Introduction to Molecular Anthropology. New Jersey: John Wiley \& Sons.

TallBear, Kim 2013. Native American DNA: Tribal Belonging and the false Promise of Genetic Science. Minneapolis: University of Minnesota Press.

Wade, Peter, Carlos López Beltrán, Eduardo Restrepo und Ricardo Ventura Santos (Hg.) 2014. Mestizo genomics: race mixture, nation, and science in Latin America. Durham und London: Duke University Press.

Wailoo, Keith, Alondra Nelson und Catherine Lee (Hg.) 2012. Genetics and the unsettled past: the collision of DNA, race and history. New Brunswick, New Jersey und London: Rutgers University Press.

Waples, Robin S. und Oscar Gaggiotti 2006. What is a Population? An Empirical Evaluation of some Genetic Methods for Identifying the Number of Gene Pools and their Degree of Connectivity. Molecular Ecology (15): 1419-1439.

\author{
Veronika Lipphardt \\ University College Freiburg \\ Bertoldstraße 17 \\ 79098 Freiburg \\ veronika.lipphardt@ucf.uni-freiburg.de
}




\section{Ancient DNA: Chancen und Herausforderungen}

Elsbeth Bösl

\section{Neue Quellen}

In den letzten Jahren wurden einige naturwissenschaftliche Methoden entwickelt, mit deren Hilfe qualitativ neuartige Daten über die Vergangenheit generiert werden können (Samida \& Feuchter 2016). So kann beispielsweise organisches Material aus archäologischen Funden auf den Ebenen der DNA- oder Proteinmoleküle oder auch anhand der in ihnen angelagerten stabilen Isotope analysiert werden. Nicht nur ganze Organismen, sondern Daten, die aus Körpersubstanzen gewonnen werden, werden zur Quelle. Im Folgenden steht ein Forschungsfeld im Mittelpunkt, das seit den 1980er Jahren auf der Basis von DNA-Sequenzen und deren Entwicklung über die Zeit teils neue, teils punktuell andere Geschichtserzählungen hervorbringt. Seine Fragestellungen sind evolutions- und umwelthistorischer, archäologischer und paläoepidemiologischer, vor allem aber auch populationsgenetischer Natur. Die Impulse gingen nicht von den historischen Wissenschaften aus, sondern primär von biologischer Anthropologie, Molekular- und Populationsgenetik. Seit der Mitte der 2000er Jahre können dank der Next Generation Sequencing-Verfahren schnell und kostengünstig ganze Genome sequenziert werden. Anhand von rezenten oder alten DNA-Sequenzen aus archäologischen Funden lassen sich unter anderem die genetische Diversität innerhalb einer Gruppe und die genetischen Beziehungen zwischen Gruppen sowie deren demografische Strukturen und Populationsdynamiken untersuchen (ausführlich Bösl 2017). Populationsgenetische Studien verfolgen einen erklärenden Makroapproach, interessieren sich für Kausalitäten und die big pictures vor allem der Menschheitsgeschichte. Dieser Zweig weckt regelmäßig das Interesse der medialen Öffentlichkeit mit neuen, aufregenden Meldungen. Scheinbar leicht und eingängig werden große Fragen beantwortet: „Woher kommen wir?", „Was macht uns aus?“, „Was verbindet uns mit unseren Vorfahren?“. Weniger beachtet werden beispielsweise die paläobiologischen Studien zu Domestikation von Tieren und Pflanzen (z. B. Bollongino 2010), die wesentliche Daten zur Siedlungs-, Wirtschafts- und Umweltgeschichte beitragen können. Fast ausschließlich Medizinhistoriker*innen rezipierten bisher die paläoepidemiologischen und -pathologischen Forschungen zur Evolution von Krankheitserregern (Feldman et al. 2016; Müller \& Roberts \& Brown 2014). Ein Schwerpunkt liegt hier auf der Pestforschung, wo historische, archäologische, kultur- und 
sprachwissenschaftliche, genetische und parasitologische Erkenntnisse bereits seit einiger Zeit verknüpft werden (Little 2011; Green 2014).

Mit dem historischen Einzelfall und damit jener Ebene, für die sich die Geschichtswissenschaft und die Archäologien besonders interessieren (so auch im NTM-Forum: Meier \& Patzold 2018: 328), befassen sich die großen populationsgenetischen Labore selten. Bei einer entsprechenden Hypothese werden aber auch Einzelfunde untersucht - beispielsweise auf genetische Verwandtschaftsbeziehungen, genetisches Geschlecht oder bestimmte Krankheitserreger hin. In solchen Fällen kontaktieren Archäolog*innen häufig Arbeitsgruppen der Paläogenetik oder molekularen Anthropologie. Solche Auftragsvergaben entsprechen einer lang etablierten Praxis der Kooperation zwischen Archäologien und Anthropologien, deren Nutznießer*innen in der Regel eher die Archäolog*innen oder die Denkmalpflege sind (Haak et al. 2010; Sallares, Bouwman \& Anderung 2004).

\section{Unterschiede und Gemeinsamkeiten}

Was ist von der neuen Art der Geschichtsschreibung zu halten? Ohne künstlich das Bild der Two Cultures - der erklärenden Naturwissenschaften im Vergleich zu den auf das Verstehen der kulturellen und sozialen Welt spezialisierten Geisteswissenschaften aufzurufen, gibt es zwischen Natur- und Geisteswissenschaften Unterschiede in den Zugängen zur Vergangenheit. Doch gibt es eben auch Ähnlichkeiten und Gemeinsamkeiten: Erstens vereint gerade die Geschichtswissenschaft seit den 1960er Jahren erfolgreich hermeneutische und analytische Zugänge. Zudem sind Historiker*innen mit ihrer lang erarbeiteten Expertise für Quellenkritik prädestiniert, sich die Chancen und Grenzen der molekularen Quellen und der Analyseverfahren erklären zu lassen und Standards für deren Einsatz mit zu entwickeln.

Zweitens weisen alle Vergangenheitsspuren, die als historische Quelle herangezogen werden, prinzipielle Aussagegrenzen sowie im Wesentlichen die gleichen Charakteristika auf - sei es nun DNA, Artefakt oder Schriftgut; und zwar, weil diese Spuren nicht von sich aus in der Welt sind, sondern von Menschen zur Klärung von menschengemachten Fragestellungen an die Vergangenheit gesucht und herangezogen werden. Kein Wissensbestand ist per se gewisser, kein Datenerhebungsverfahren sicherer, keine Quelle mächtiger oder objektiver. Gerade die DNA-Sequenzen werden von Menschen aufwändig als Quelle hergestellt: bei der Beprobung, im Labor, am Rechner. Perspektivität, Standortgebundenheit und Selektivität gehören zu ihren Eigenschaften. Wird DNA-Material aus archäologischen Funden extrahiert - man kann alternativ bei manchen populationsgenetischen 
Fragestellungen aus rezenten Proben quasi zurückrechnen, dann aber den Faktor Zeit weniger gut einbeziehen - sind die epistemischen Ressourcen begrenzt: Ein Bruchteil der Artefakte und Organismen der Vergangenheit ist erhalten und jeder Fund ist letztlich zufällig (Feuchter 2018: $342 \mathrm{f}$; Hofmann 2015: 458f.). Diese Limitationen erzwingen den, in den Laborwissenschaften eher unbeliebten, materialgeleiteten Zugang: Analysiert wird, was geborgen wurde. Auch in Zeiten genomweiter Sequenzierungsverfahren ist das Sample oft klein. Obwohl sich mithilfe weniger Genome Daten über ganze Populationen errechnen lassen, steht die Repräsentativität der generierten Daten oft in Frage (Haak \& Schiffels 2018: 320-322 vs. Meier \& Patzold 2018: 327).

Hilfreich könnte für das überfachliche Miteinander eine konstruktivistische Sichtweise sein: Wer in Daten Produkte aus menschlicher Herstellung sieht, wird weniger nach universellen Gewissheiten suchen, als damit rechnen, dass Szenarien, die im Moment als haltbar gelten, in Kürze als revisionsbedürftig wahrgenommen werden (Keupp 2018: 334-335; Feuchter 2018: 341). Die Wissenschaftsgeschichte jedenfalls kennt rasche Abfolgen gegenteiliger Forschungsstände und Interpretationen.

Drittens, und in dieser Gemeinsamkeit liegt erhebliches Konfliktpotential, erheben im Feld der Genetic History nun die Naturwissenschaften einen gewissen Anspruch auf die soziokulturelle Sinnstiftung, die einstmals, stark vereinfacht ausgedrückt, im Ausschlussverfahren den Geisteswissenschaften überlassen worden war. Das führt etwa zwischen prähistorischen Archäolog*innen und Populationsgenetiker*innen regelmäßig zu Konflikten in der Frage, wer die Deutungshoheit über die Vergangenheit besitzt - und aufgrund welcher Quellen und Verfahren. Während sich die prähistorische Anthropologie, die Paläobotanik und andere Fächer lang in die Rolle der Ancilla-Wissenschaften fügten und auf Zuruf Daten an die archäologischen Projekte lieferten, ist es unrealistisch zu erwarten, dass die Populationsgenetik sich in ähnlicher Weise zur punktuell einzusetzenden Hilfsmethode degradieren lassen wird, wie Meier \& Patzold dies vorschlagen (2018: 329).

Die Herausforderung besteht darin, zu einem überfachlichen Miteinander zu finden, in dem Daten in enger Absprache generiert und interpretiert werden. Dabei winken Chancen auf neue Erkenntnispotentiale und eine integrierte Perspektive auf die Vergangenheit, aber Konflikte und Reibungsverluste werden unvermeidbar sein. Bisher traf dies primär die Archäologien, doch sind etliche Anwendungsfelder denkbar, die für die Allgemeine Geschichtswissenschaft, vor allem die Mediävistik, interessant sein können. Historiker*innen können davon profitieren, dass in den Archäologien seit Jahren wichtige epistemologische und fachpolitische Fragen diskutiert werden: Welche Konsequenzen könnte der Einsatz naturwissenschaftlicher Ways of Knowing für die historischen Wissenschaften haben? Wie viel 
Naturwissenschaftliches „vertragen“ die Archäologien? (Samida \& Eggert 2013; Killick 2015; Lidén \& Eriksson 2013; Larsson 2013; anders Kristiansen 2014: 20-22, 27).

Immer wieder geht es um die Frage, ob und wie die jeweiligen Quellen und Konzepte der Bio-, Kultur-, Sozial- und Geschichtswissenschaften miteinander in Verbindung gebracht werden können (Burmeister 2013; Siegmund 2014). Vehement wird zum Beispiel das Konzept Migration debattiert. Die europäischen Archäologien haben hier in den letzten fünf Jahrzehnten bewusst auf große Narrative verzichtet. Wer Prozesse von Mobilität und Migration untersucht, mahnt vielmehr zu maximaler Genauigkeit und Differenzierung (im NTM-Forum: von Rummel 2018: 345; anders Haak \& Schiffels 2018: 319; zur Debatte Bösl 2017). Die adressierten historischen Phänomene gelten als hochkomplex. Das Unterfangen, soziokulturelle Begriffe wie archäologische Kultur, Technokomplex oder ethnos mit biologischen Gruppenbegriffen in Verbindung zu setzen, gilt als prekär. Ist zusätzlich von Identität die Rede, sind Konflikte vorgezeichnet. Als der Genetiker David Reich erklärte, Identität sei vorrangig genetisch definiert und entstehe durch biologische und geografische Migrationen (Reich 2018), rief dies unter Geschichts- und Kulturwissenschaftler*innen (und in den Feuilletons) Aufregung hervor (Lewis-Kraus 2019; Callaway 2018; Feuchter 2019). Die geschichts-, sozial- und kulturwissenschaftliche Forschung fasst seit Jahrzehnten die Bildung von Identitäten als sehr komplexen Prozess mit vielen Variablen auf und fordert Aufmerksamkeit für Kontingenz und Uneindeutigkeiten. Eine genetische Identitätskomponente ist aus dieser Sicht ein Teilchen von vielen. Reich und andere rufen die Sorge hervor, dass soziokulturelle Kategorien wie race, Ethnizität oder Geschlecht naturalisiert und essentialisiert werden könnten. Gewarnt wird auch vor wissenschaftlich verbrämten Neuauflagen des Rassismus (Marks 2018; Holmes 2018).

Tatsächlich ist es problematisch, wenn aus den Laboren der sogenannten exakten Wissenschaften, die ohnehin aus historischen Gründen einen Glaubwürdigkeitsvorsprung in der öffentlichen Wahrnehmung haben, scheinbar eindeutige und leicht verständliche Evidenzen kommen, die in der Wahrnehmung des Publikums die differenzierten, aber oft sperrigen Antworten der Geschichtswissenschaft oder Archäologien überrollen. Zudem erwiesen sich gerade große Entwürfe der Populationsgenetik als nicht besonders haltbar (dazu Keupp 2018: 335; von Rummel 2018: 349). Infolge von technischen Innovationen, veränderten Qualitätskriterien und neuen Funden kehren sich manche Forschungsstände schnell um. Angesichts der anhaltenden Authentifizierungsprobleme der aDNA-Forschung fällt es manchmal schwer, ihren Gewissheitsversprechen und „Beweisketten“ zu vertrauen (Haak \& Schifffels 2018: 313). Beispielhaft verdeutlichen lässt sich das anhand der Bestimmung des molekularen Geschlechts, hier im Einzel- 
nen anhand einer reichen alamannischen Dreifachbestattung in Niederstotzingen/Heidenheim aus dem 6./7. Jahrhundert: Ende der 1990er Jahre wurde eine aDNA-Analyse vorgenommen. Diese ergab, dass das Individuum 3C, das in den 1960er Jahren von einem Anthropologen auf der Basis der Knochenmorphologie als graziler Mann angesprochen und aufgrund der Waffenausstattung archäologisch ebenfalls als Mann bezeichnet worden war (Creel 1967: 27 f.; Paulsen 1967: $27 \mathrm{f}$. und 182-185), eine genetische Frau sei (Zeller 2000: 115). Handelte es sich um den sensationellen genetischen Nachweis einer „Frau in Waffen“, die auf der Basis der traditionellen archäologischen und anthropologischen Methoden unentdeckt geblieben wäre (u.a. Schneider 2008: 9, 13)? Würden aDNA-Daten archäologische Befunde laborwissenschaftlich revidieren bzw. validieren, vielleicht sogar nicht-binäre Geschlechterverhältnisse in der Vergangenheit aufdecken? Erneute Analysen ergaben 2013/2014, dass die Bestimmung von 3C auf einer inzwischen veralteten Vorgehensweise beruhte (Wahl et al. 2014: 379f.). Nun lautete der Befund wieder: genetisch und morphologisch männlich. Die „Frau in Waffen“ war verschwunden. In weiteren vergleichbaren Divergenzfällen war es ähnlich. Da die Validität von Verfahren und Qualitätsstandards wissenschaftlicher Arbeit häufig neu verhandelt werden muss, kann auch dieser Befund mit der Zeit als überholungsbedürftig gelten - ein normales Kontingenzphänomen in allen Wissenschaften. Alte DNA garantiert also nicht wie eine truth machine eine universale Antwort.

Vorsicht gegenüber den Erkenntnisgrenzen und Problemen der molekulargenetischen Methoden ist berechtigt und wird immer häufiger im Feld selbst laut (z. B. Jobling, Rasteiro \& Wetton 2016; Thomas 2013). Historiker*innen sind außerdem gefordert, fachfremde Kolleg*innen mit den Denkweisen und Regeln der Geschichtswissenschaft in Kontakt zu bringen. Das beinhaltet vernünftigerweise, auch über die eigenen methodischen Grundsätze und Szenarien nachzudenken und deren Validität zu prüfen. Da wissenschaftliche Aussagen auf ihrem Weg durch die gestuften Öffentlichkeiten dazu tendieren, gewisser und eingängiger daherzukommen, als sie es ursprünglich waren, und von den soziokulturellen Bedingungen ihrer Produktion bereinigt zu werden, ist es wichtig, diese Öffentlichkeiten stärker an überfachlichen Diskussionen über Methodenprobleme und Quellen-Vetos teilhaben zu lassen.

Vorstellbar sind auch Begleitforschungen der Wissenschafts- und Zeitgeschichte für größere, vor allem populationsgenetische Projekte. Ein ethnografischer Zugang im Sinn der Lab Studies könnte sehr interessant sein, um die spezifischen Produktionsbedingungen von Wissen in solchen Projekten kennenzulernen und vielleicht Ideen für best practice Konzepte zur interdisziplinären Zusammenarbeit zu sammeln. 


\section{Literatur}

„How Not To Talk About Race And Genetics“, 30.03.2018. URL: https://www.buzzfeednews.com/article/bfopinion/race-genetics-david-reich, zuletzt aufgerufen am 04.02.2019.

Bollongino, Ruth und Mark G. Thomas 2010. The Palaeopopulationgenetics of Humans, Cattle and Dairying in Neolithic Europe. In: Ron Pinhasi und Jay T. Stock (Hg.). Human Bioarchaeology of the Transition to Agriculture. Hoboken: Wiley-Blackwell: 370-384.

Bösl, Elsbeth 2017. Doing ancient DNA. Zur Wissenschaftsgeschichte der aDNA-Forschung, Bielefeld: transcript.

Bösl, Elsbeth und Jörg Feuchter, erscheint 2019/2020. Emerging Fields Essay: Genetic History. NPL.

Burmeister, Stefan 2013. Migration und Ethnizität: Zur Konzeptionalisierung von Mobilität und Identität. In: Manfred K.H. Eggert und Ulrich Veit (Hg.). Theorie in der Archäologie. Zur jüngeren Diskussion in Deutschland. Münster: Waxmann: 229-268.

Callaway, Ewan 2018: The Battle for Common Ground. Nature (555): 573-576.

Creel, Norman 1967. Die menschlichen Skelettreste. In: Peter Paulsen (Hg.). Alamannische Adelsgräber von Niederstotzingen (Kreis Heidenheim), Bd. 2. Stuttgart: Müller \& Gräff: 27-32.

Feldman, Michal, Michaela Harbeck und Marcel Keller et al. 2016. A High-Coverage Yersinia pestis Genome from a Sixth-Century Justinianic Plague Victim. Molecular Biology and Evolution (33): 2911-2923.

Feuchter, Jörg 2018. Für einen kritischen Dialog zwischen Geschichtswissenschaft und genetic history. NTM (26): 339-344.

Feuchter, Jörg 2019. Ozeanische Stichprobe. Frankfurter Allgemeine Zeitung, 30.01.2019.

Green, Monica H. 2014. Genetics as a Historicist Discipline: A New Player in Disease History, Dezember 2014. AHR Perspectives on History. URL: https://www.historians.org/ publications-and-directories/perspectives-on-history/december-2014/genetics-as-ahistoricist-discipline, zuletzt aufgerufen am 01.11.2018.

Haak, Wolfgang, Guido Brandt und Christian Meyer et al. 2010. Die schnurkeramischen Familiengräber von Eulau - ein außergewöhnlicher Fund und seine interdisziplinäre Bewertung. In: Harald Meller und Kurt W. Alt (Hg.). Anthropologie, Isotopie und DNA - biografische Annäherung an namenlose vorgeschichtliche Skelette? 2. Mitteldeutscher Archäologentag vom 8.-10.10.2009 in Halle (Saale), Halle: Beier \& Beran: 53-61.

Hofmann, Daniela 2015. What Have Genetics Ever Done for Us? The Implications of aDNA Data for Interpreting Identity in Early Neolithic Central Europe. European Journal of Archaeology (18): 454-476.

Holmes, Ian 2018. What Happens When Geneticists Talks Sloppily About Race. The Atlantic, 25.03.2018.

Jobling, Mark A., Rita Rasteiro und Johan H. Wetton 2016. In the Blood: The Myth and Reality of Genetic Markers of Identity. Ethnic Racial Studies (39): 142-161.

Keupp, Jan 2018. Geistlose Geschichte oder historisierte Genetik? Überlegungen eines „Gatekeepers". NTM (26): 331-338.

Killick, David 2015. The Awkward Adolescence of Archaeological Science. Journal of Archaeological Science (56): 242-247.

Kristiansen, Kristian 2014. Towards a New Paradigm? The Third Science Revolution and its Possible Consequences in Archaeology. Current Swedish Archaeology (22): 11-34.

Larsson, Åsa M. 2013. Science and Prehistory. Are We Mature Enough to Handle it? Current Swedish Archaology (21): 27-33.

Lewis-Kraus, Gideon 2019. Is Ancient DNA Research Revealing New Truthsor Falling Into Old Traps?, 17.01.2019. URL: https://www.nytimes.com/2019/01/17/magazine/ancient-dnapaleogenomics.html, zuletzt aufgerufen am 19.01.2019.

Lidén, Kerstin und Gunilla Eriksson 2013. Archaeology vs. Archaeological Science. Do We Have a Case. Current Swedish Archaology (21): 11-20. 
Little, Lester K. 2011. Review Article: Plague Historians in Lab Coats. Past E Present (213): $267-290$.

Marks, Jonathan 2018. There's an arrogant anti-intellectual hereditarian at Harvard who isn't Steven Pinker! Who would have thunk it?, anthropomics2.blogspot.de, 23.03.2018. URL: http://anthropomics2.blogspot.com/2018/03/, zuletzt aufgerufen am 09.11.2018.

Meier, Mischa und Steffen Patzold 2018. Big Picture? Anmerkungen zu DNA-Analysen und historischen Fragestellungen. NTM (26): 325-330.

Müller, Romy, Charlotte A. Roberts und Terence A. Brown 2014. Genotyping of Ancient Mycobacterium Tuberculosis Strains Reveals Historic Genetic Diversity. Proceedings of the Royal Society, Biological Sciences (281): 20133236.

Paulsen, Peter 1967. Alamannische Adelsgräber von Niederstotzingen (Kreis Heidenheim). Stuttgart: Müller \& Gräff.

Reich, David 2018. Who We Are and How We Got Here. Ancient DNA and the New Science of the Human Past. New York: Oxford UP.

Rummel, Philipp von 2018. Gene, Populationen und Identitäten: Genetic History aus archäologischer Sicht. NTM (26): 345-350.

Sallares, Robert, Abigail S. Bouwman und Cecilia Anderung 2004. The Spread of Malaria to Southern Europa in Antiquity: New Approaches to Old Problems. Medical History (48): 311-328.

Samida, Stefanie und Manfred K.H. Eggert 2013. Archäologie als Naturwissenschaft? Eine Streitschrift. Berlin: Vergangenheits-Verlag.

Samida, Stefanie und Jörg Feuchter 2016. Why Archaeologists, Historians and Geneticists Should Work Together - and How. Medieval Worlds (21): 5-21.

Schneider, Thomas 2008. Mehrfachbestattungen von Männern in der Merowingerzeit. Zeitschrift für Archäologie des Mittelalters (36): 1-32.

Siegmund, Frank 2014. Kulturen, Technokomplexe, Völker und Identitätsgruppen: eine Skizze der archäologischen Diskussion. Archäologische Informationen (37): 53-65.

Thomas, Mark G. 2013. To Claim Someone Has ,Viking Ancestors' Is No Better than Astrology. Exaggerated Claims from Genetic Ancestry Testing Companies Undermine Serious Research into Human Genetic History. The Guardian, 25.02.2013.

Wahl, Joachim 2014. Neue Erkenntnisse zur frühmittelalterlichen Separatgrablege von Niederstotzingen, Kreis Heidenheim. Fundberichte aus Baden-Württemberg (34): 341-390.

Zeller, Monika 2000. Molekularbiologische Geschlechts- und Verwandtschaftsbestimmung in historischen Skelettresten, Diss. Univ. Tübingen 2000. URL: http://docplayer.org/14338829-Molekularbiologische-geschlechts-und-verwandtschafts-bestimmungin-historischen-skelettresten.html, zuletzt aufgerufen am 01.03.2018.

\section{Elsbeth Bösl}

Universität der Bundeswehr München

Historisches Institut

Werner-Heisenberg-Weg 39

85577 Neubiberg

elsbeth.boesl@unibw.de 


\section{Consilience in der Vormoderne - Anmerkungen aus der Klima- geschichte}

Martin Bauch

Der US-Soziobiologe Edward O. Wilson legte 1998 eine Monographie vor, die unter dem Begriff consilience die Einheit des menschlichen Wissens proklamierte (Wilson 1998) und so einmal mehr die Überwindung der 1959 von Charles Percey Snow benannten „Zwei Kulturen“ anstrebte. Ein Produkt des 19. Jahrhunderts (Whewell 1840: II, 230-231), bezeichnet der Neologismus consilience den überragenden epistemologischen Wert von Aussagen, die auf unterschiedlichen Klassen von Fakten beruhen. Einfacher gesagt: Wenn sich mindestens zwei in ihren Erkenntnismethoden völlig unabhängige Disziplinen dem gleichen Problem widmen und dabei zu übereinstimmenden Befunden kommen, können diese Ergebnisse eine höhere Wertigkeit beanspruchen als solche, die nur aus einer Disziplin allein stammen. Wilson zielte mit seiner Forderung allerdings kaum auf die historischen Disziplinen ab; und selbst in der von ihm anvisierten Zielgruppe der gegenwartsorientierten Sozial- und Kulturwissenschaften blieb die Reaktion eher zögerlich (Slingerland \& Collard 2012). Im Kontext der hier verhandelten Diskussion zur Genetic History fällt auf, dass consilience für die Klimageschichte ganz ähnliche Probleme aufwirft, wenn es um den Einbezug naturwissenschaftlicher Methoden in historische Forschung und dadurch entstehende Fallstricke geht.

Für die relativ junge Disziplin der Klimageschichte (umfassender Überblick: White, Pfister \& Mauelshagen 2018), die sich von Anfang an als interdisziplinär arbeitend verstanden hat, ist consilience keine revolutionäre Neuerung. Ausgehend von einer initialen Konferenz 1979 (Rotberg \& Rabb 1981) suchte sie seit den 1980er Jahren in Hinblick auf die Rekonstruktion vergangener klimatischer Bedingungen und meteorologischer Extremereignisse aus Schriftquellen den engen Schulterschluss zu historischer Klimatologie und Geowissenschaften (Mauelshagen 2009). Dies hat jedoch eher zu ihrer langjährigen Randständigkeit in der Geschichtswissenschaft insgesamt, ja sogar innerhalb der Umweltgeschichte (Mauelshagen 2010: 29) beigetragen. Innerhalb der Klimageschichte erfolgte im Lauf der 1990er Jahre und nach der Jahrtausendwende eine Neuausrichtung, weg von der Rekonstruktion von Mittelwerten über lange Zeiträume hin zu Anomalien und Extremereignissen, aus denen die historische Katastrophenforschung als neues Hauptarbeitsfeld der Klimahistoriker hervorging (Mauelshagen 2009: 181 f.; Schenk 2014). 
Eine Perspektivverschiebung aus der vormodernen Allgemeingeschichte im Hinblick auf die Bedeutung natürlicher Rahmenbedingungen für historische Prozesse fand aber nur punktuell statt (z. B. McCormick 2007); besonders einflussreich ist aus dem Bereich postkolonialer Studien der Beitrag von Dipesh Chakrabarty über „The Climate of History“ (Chakrabarty 2009), der im Kontext der Anthropozän-Debatte Klimaveränderungen und ihren Impact auf historische Prozesse als Thema für die Geschichtswissenschaft hervorhob.

Doch ein expliziter Rückgriff auf Wilson erfolgte erst 2011 in einer programmatischen Rezension im Journal for Interdisciplinary History, in dem consilience als „contribution of the natural sciences to elucidating the human past, and [...] of human history to clarifying and explaining the process of nature“ (McCormick 2011: 257 f.) eingeführt wurde. Diese „broad-spectrum history“ (ebd.: 258) wurde von Michael McCormick ausdrücklich mit dem Verweis auf paläogenetische Forschungen begründet und programmatisch ausgedehnt auf Epochen mit relativ dünner schriftlicher Überlieferung, in denen "the demand of new data is strongest" (ebd.). Und so haben nicht nur erste Studien der Genetic History, sondern auch der Klima- und Epidemiegeschichte vom Einbezug naturwissenschaftlicher Daten profitiert (McCormick \& Büntgen et al. 2012; Gogou, Izdebski \& Holmgren 2016; Newfield \& Labuhn 2017; Haldon et al. 2018). Häufig geht es dabei auch darum, wie Geistes- und Naturwissenschaftler*innen zu einer gemeinsamen Sprache zu für alle Beteiligten relevanten Fragen finden und wie zeitliche und geographische Skalen in Übereinstimmung gebracht werden können (Izdebski et al. 2016). Die Chance, ja Verlockung für die historische Forschung zur Vormoderne - eine substantielle Verbreiterung der Quellenbasis - ist dabei ebenso offenkundig wie die Gefahr der Degradierung der historischen Befunde zur Zweitrangigkeit, die für einige der neueren Studien von jahrgenauen Proxydaten ausgeht, wenn sie mit sehr verstreuten Schriftquellen zusammengebracht werden: „the natural world tends to predominate in dark ages" (Newfield \& Labuhn 2017: 215). Diese Problemlage stellt sich vergleichbar auch für die genetic history. Daher ist zu Recht festgestellt worden, dass der Königsweg bei künftigen Studien läge, für die man sicher sagen könne: „data, both historical and scientific, are dense“ (ebd.: 214).

Erste Schritte in diese Richtung, aber auch erkennbare Fehlentwicklungen sollen an einem Beispiel diskutiert werden, das Umwelt-, Epidemieund Montangeschichte sowie geowissenschaftliche Eisbohrkernforschung gleichermaßen berührt und zugleich in den relativ überlieferungsdichten Jahrhunderten des Spätmittelalters angesiedelt ist. Im Jahr 2017 machte ein Artikel auch in nicht-wissenschaftlichen Medien Furore, der die Bleikonzentration in einem Eisbohrkern aus dem Colle-Gniffetti-Gletscher an der italienisch-schweizerischen Grenze mit historischen Befunden aus dem 
14. Jahrhundert in Verbindung brachte (More et al. 2017). Die Autor*innen entstammen überwiegend der in Harvard etablierten Initiative for a Science of the Human Past, die sich von Anfang an eine weitgehende Integration historischer und naturwissenschaftlicher Forschung zum Ziel gestellt hat und deren erste Ergebnisse ausgesprochen offensiv propagiert. Als Resultat der genannten Studie wurde ein Absinken des anthropogenen Bleieintrags im Eisbohrkern unter die Nachweisgrenze genau für die Hochphase des Schwarzen Todes (1349-1353) in Europa konstatiert - was einem einmaligen Vorgang für die letzten 2000 Jahre gleichkommen würde.

Auf den ersten Blick erfüllt die Studie die oben genannten Anforderungen, Proxydaten - in diesem Fall aus einem alpinen Eisbohrkern - mit dichter schriftlicher Dokumentation zu kontrastieren und so den consilient approach to history Realität werden zu lassen: Die jahrgenau differenzierbaren Schichten des Eisbohrkerns wurden für jüngere Epochen durch aus dem historischen Befund entnommene Saharastaubstürme kalibriert (More et al. 2017: 212) und zudem mit C14-Untersuchungen organischen Materials grobdatiert. Die technische Fehlermarge der rein naturwissenschaftlichen Datierung des Eisbohrkerns wurde, warum auch immer, erst in einem späteren Beitrag expliziert und beträgt für das 14. Jahrhundert 35-40 Jahre (Bohleber et al. 2018: 27 f., Tab. 3; Loveluck et al. 2018: 5).

Entscheidend ist also, warum die Minima im Bleieintrag des Eisbohrkerns - deren Faktizität historische Forschung nicht in Frage stellen kann - mit dem massiven Rückgang, ja sogar „Kollaps“ europäischer Bleiverhüttung im Kontext der Pest in Verbindung gebracht werden. Haben die beteiligten Geschichtswissenschaftler*innen hier historische Quellen herangezogen, um einen Eisbohrkernbefund zu erklären, oder liefert der Eisbohrkernbefund einen Beitrag zur Geschichte des Schwarzen Todes? Sind die beteiligten Disziplinen gleichberechtigt in der Erklärungskraft ihrer Befunde oder gibt es dienende und dominante Rollen unter dem Mantel der consilience?

Aus dem atmosphärischen Transport moderner Umweltgifte in den Eisbohrkern wurde geschlossen, dass vor allem Bleiverhüttung in England, Frankeich und Deutschland Niederschlag im Alpengletscher gefunden haben könnte (More et al. 2017: 216). Zugleich wurde aus dem einschlägigen Übersichtwerk zum mittelalterlichen Hüttenwesen und Metallbergbau in Europa (Blanchard 2005) eine überragende Dominanz englischer Bleiproduktion Mitte des 14. Jahrhunderts konstatiert, während die Produktion im Harz seit den 1330er Jahr als erloschen charakterisiert wurde (ebd.: 14641465), obwohl deutschsprachige Literatur ein Ende des Harzbergbaus allgemein erst um 1360 feststellt (Kaufhold 2000: 43; Bartels 2010: 75-76). Die gemeinhin von Historikern als ähnlich wichtig wie die englische charakterisierte (Blanchard 2005: 1465) polnische Bleiproduktion hatte die Studie gar nicht erwähnt, obwohl etwa oberungarische Befunde auf eine durch die Pest 
nicht wesentlich unterbrochene Blütezeit der Bleiförderung in Ostmitteleuropa hindeuten (Batizi 2018: 176). Auch die böhmischen Bleiminen und -hütten um Jihlava produzierten ohne klar erkennbaren Einschnitt zwischen 1240 und 1380 (Majer 2000: 73). Die bedeutende Bleiförderung in Sardinien hatten die Autor*innen aus Gründen der atmosphärischen Zirkulationsmuster nicht in ihre Überlegungen aufgenommen (More et al. 2017: 216). Selbst diese erfährt durch die Pestepidemie zwar eine Halbierung der Produktion (Tangheroni 1984: 16-17 anstelle der zitierten, eher oberflächlichen Handbuchdarstellung Anatra 1989: 116), und doch gibt es eine Kontinuität der Bleiverhüttung bis 1363, die Marco Tangheroni ausdrücklich als relativ unabhängig von den Pestauswirkungen charakterisiert (Tangheroni 1984: 15, 25). Nach diesem europaweiten Panorama zur Bleiförderung im 14. Jahrhundert, müssen noch die vier Bergbauregionen im Süd- und Nordwesten Englands mit hoher Bedeutung für die europäische Bleiproduktion genauer betrachtet werden. Für Mendip ist tatsächlich ein Kollaps nach 1348 (Blanchard 2005: 1407) festzustellen, während der Niedergang der Produktion in Devon schon 1343/44 einsetzte (ebd.: 1695-1697). Eine eher assoziative Zuordnung des Produktionsrückgangs mit der Pest nimmt Blanchard für Flintshire (ebd.: 1381) vor; und in Derbyshire findet sich eine retrospektive Argumentation: 1353 liegen Beschwerden über den Mangel an Arbeitskräften vor, während ein starker Rückgang der Bleiproduktion schon ab 1345 einsetzt (ebd.: 1695).

Zweifellos gab es eine Krise des europäischen Montanwesens in der Mitte des 14. Jahrhunderts, und die Pest dürfte dabei eine Rolle gespielt haben (Bartels 2000: 171). Doch letztlich ist die Verknüpfung von Pestmortalität und dem aus einem Bohrkern erschlossenen Rückgang der Bleiproduktion auf Null nicht, oder nur in Einzelfällen möglich. Selbst wenn sich aus Gründen der Luftzirkulation wirklich nur die englische Bleiverhüttung der Mitte des 14. Jahrhunderts im Eiskern von Colle Gniffetti spiegeln sollte, müsste man doch von einem vergleichbar verheerenden Impact der Pest auf Minen und Hütten im restlichen Europa ausgehen. Die Verengung auf die Bleiförderung und -gewinnung, die More et al. vornehmen, resultiert zwar aus den vorhanden Proxydaten, sie müsste aber - wenn der Bleigehalt des Bohrkerns plausibel die Wucht der Pest spiegeln soll - die Folgen des Schwarzen Todes auch für andere Bereiche spätmittelalterlichen Wirtschaftens diskutieren: Warum sollte etwa die Produktion von Eisen weniger von der Reduktion der verfügbaren Arbeitskräfte betroffen sein als die von Blei? Doch etwa in den französischen Fördergebieten der Zentralpyrenäen ist keine Unterbrechung feststellbar - noch im Dezember 1349 wird eine neue mouline à fer errichtet, eine hydraulisch unterstützte Anlage zur Zerkleinerung des Erzes (Verna 2001: 338-339). Und waren Arbeitskräfte der einzige Faktor, der die Bleiproduktion und somit das Signal im Colle-Gnifetti-Eis- 
bohrkern beeinflusste? So wird etwa der Nachfragerückgang genauso wenig diskutiert wie der Effekt von Wassereinbrüchen in Minen, der beispielsweise in Polen Mitte des 14. Jahrhunderts ein gravierendes Problem darstellte (Molenda 1976: 154-155) und im Kontext der Klimaverschlechterung des 14. Jahrhunderts möglicherweise zunahm.

Das Beispiel von Eisbohrkernanalyse, historischer Bleiproduktion und Pestimpact zeigt das grundsätzliche Problem an: Ausgangspunkt ist die Erklärung eines naturwissenschaftlich nur mit großer Fehlermarge datierbaren Eisbohrkernbefundes unter Ausklammerung großer Teile des Forschungsstandes der Geschichtswissenschaft zu den Folgen der Pest, kombiniert mit selektiver Quellenauswahl. In dieser Form betrieben, droht consilience also den eigenen Anspruch nicht mehr einzulösen, sondern zur Einbahnstraße zu werden. Sogar in Perioden dichterer schriftlicher Überlieferung geht es "about the ways history can contribute to the paleosciences“ (Haldon et al. 2018: 2), wie es selbst der ansonsten differenziert argumentierende Byzantinist John Haldon durchaus affirmativ formuliert.

Dabei ist die Zielrichtung zwar zu einseitig, aber nicht grundsätzlich abzulehnen, wenn man den tatsächlich fundamentalen Beitrag betrachtet, den historische Daten beispielsweise zur Feindatierung naturwissenschaftlicher Proxies leisten können, etwa im Nachweis vulkanischer Großeruptionen. Schriftliche Befunde, die - zu Recht oder zu Unrecht, und nicht unähnlich dem hier diskutierten Beispiel - als klare Indikatoren vulkanischer Trockennebel verstanden werden, dienen als "stratigraphische Marker“ in der Feindatierung von erhöhten Schwefeleinträgen in Eisbohrkernen polaren Ursprungs (Bauch 2017). Im Fall der Blei- wie der Schwefelkonzentration in Eisbohrkernen dürfen die involvierten Angehörigen der Geschichtswissenschaft keiner unzulässigen Reduktion der Komplexität historischer Forschungsergebnisse das Wort reden, wie es für den Beitrag von More et al. 2017 hier demonstriert wurde, wenn es um denkbare Folgen des Pestimpacts geht. Vielmehr sind die zu beantwortenden Fragestellungen aus der eigenen Disziplin heraus zu entwickeln und sollten sich nicht zuerst an der Verfügbarkeit von Proxydaten orientieren.

Ein wie gezeigt selektiver Umgang mit Quellenbefunden führt dann wiederum zur Herstellung nur scheinbar präziser Chronologien in den Proxydaten:

„[D] espite a theoretical error of 35-40 years, between 1330 and 1370, the total collapse in lead pollution in layer-counted deposits, from 1349 to 1353, matches exactly the absolute chronology from textual sources for the Black Death epidemic." (Loveluck et al. 2018: 5)

Wie wir gesehen haben, ist die Chronologie der Bleiproduktion um den Schwarzen Tod herum alles andere als widerspruchsfrei. Wer also mit Verve - und natürlich zu Recht - den Wert historischer Quellen für präzise Da- 
tierungen gegenüber Kritikern anführt (More et al. 2018: 163), muss diesen Anspruch bei der Anwendung von Quellenkritik selbst erfüllen. Andernfalls pflanzen sich Kalibrierungsfehler durch unzuverlässige „historische Fakten" in nur scheinbar absoluten Chronologien über lange Zeiträume in naturwissenschaftlichen Publikationen fort, wie es gerade für die Arbeit mit Eisbohrkernen gezeigt werden kann (Bauch 2015). Denn die Qualitätssicherung durch Reviewer ist notwendigerweise auch in hochrangigen naturwissenschaftlichen Journals überfordert, wenn dort mit nur scheinbar gesicherten historischen Befunden argumentiert wird, die aber ohne die Hinzuziehung von Geisteswissenschaftler*innen nicht als problematisch erkannt werden. Darüber hinaus sind auch von geowissenschaftlicher Seite weitreichende Argumentationsketten auf der Basis einzelner Bohrkerne zunehmend unüblich geworden (argumentierend auf Basis polarer Eisbohrkerne: Sigl et al. 2015). Freilich sind die Gegebenheiten in den Alpen so, dass dort nur an wenigen Stellen Gletscherbohrkerne entnommen werden können, die chronologisch hochauflösende Analysen zulassen. Es ist also für die Alpen kaum möglich, größere Räume durch mehrere Bohrkerne zu erschließen. Trotzdem oder gerade deswegen bleibt die Aussagefähigkeit eines Einzelbohrkerns wie der von Colle Gnifetti limitiert.

Man kann nur zustimmen: „Consilient history is at the same time both terrifying and exhilarating“ (McNeill 2018: 635) - aber nicht nur wegen der methodischen Ansprüche und vielfachen Kompetenzen, die kein Einzelforscher in sich vereinen kann. So groß wie die Chancen auf neue Erkenntnis ist die Gefahr für die Geschichtswissenschaft, als historische Hilfswissenschaft der paleosciences zu enden - ein mögliches Schicksal, das den historisch Forschenden in der Umwelt- und Medizingeschichte, Archäologie und Genetic History nicht von außen auferlegt wird, sondern in das sie sich allenfalls freiwillig begeben. Consilience als Ansatz für die Geschichtswissenschaft bleibt ein Ansporn und eine Herausforderung, die sicher nur partiell zu realisieren ist. Sie kann sich einstellen, aber das „Vetorecht der Quellen“ (Koselleck 1977) darf nicht hintergangen werden, so verlockend die Perspektiven einer Ausweitung der Zone historischer Forschung und ihrer Quellengrundlage auch sein mögen.

\section{Literatur}

Anatra, Bruno 1989. Economia sarda e commercio mediterraneo nel basso medio evo e nell'età moderna. In: Massimo Guidetti (Hg.). Storia dei sardi e della Sardegna, 3: L'etá moderna dagli aragonesi alla fine del dominio spagnolo. Milano: Jaca Book: 109-216. 
Bartels, Christoph 2000. Zur Bergbaukrise des Spätmittelalters. In: Markus Denzel (Hg.). Konjunkturen im europäischen Bergbau in vorindustrieller Zeit: Festschrift für Ekkehard Westermann zum 60. Geburtstag. Stuttgart: Steiner: 157-172.

Bartels, Christoph 2010. The Production of Silver, Copper, and Lead in the Harz Mountains from late Medieval Times to the onset of Industrialization. In: Ursula Klein (Hg.). Materials and Expertise in Early Modern Europe. Between Market and Laboratory. Chicago: Univ. of Chicago Press: 71-100.

Batizi, Zoltán 2016. Mining in Medieval Hungary. In: József Laszlovsky, Balázs Nagy, Peter Szabò und András Vadas (Hg.). The Economy of Medieval Hungary. Turnhout: Brill: 166-181.

Bauch, Martin 2017. The Day the Sun Turned Blue. A Volcanic Eruption in the Early 1460s and its Possible Climatic Impact - a Natural Disaster Perceived Globally in the Late Middle Ages? In: Gerrit J. Schenk (Hg.). Historical Disaster Experiences. A Comparative and Transcultural Survey between Asia and Europe. Heidelberg: Springer: 107-138.

Bauch, Martin 2015. Vulkanisches Zwielicht. Ein Vorschlag zur Datierung des KuwaeAusbruchs auf 1464. Mittelalter. Interdisziplinäre Forschung und Rezeptionsgeschichte. 10. April 2015. URL: http://mittelalter.hypotheses.org/5697, zuletzt aufgerufen am 15.04.2019.

Blanchard, Ian 2005. Mining Metallurgy and Minting in the Middle Ages. Vol. 3: Continuing Afro-European Supremacy, 1250-1450. Stuttgart: Steiner.

Bohleber, Pascal et al. 2018. Temperature and Mineral Dust Variability Recorded in two lowaccumulation Alpine Ice Cores over the last Millennium. Climate of the Past (14): 21-37.

Chakrabarty, Dipesh 2009. The Climate of History: Four Theses. Critical Inquiry (35/2): 197-222.

Gogoud, Alexandra, Adam Izdebski und Karen Holmgren (Hg.) 2016. Mediterranean Holocene Climate, Environment and Human Societies = Special Issue: Quaternary Science Reviews (136).

Haldon, John et al. 2018. History Meets Palaeoscience: Consilience and Collaboration in Studying past Societal Responses to Environmental Change. Proceedings of the National Academy of Sciences of the United States of America (115/13): 3210-3218.

Izdebski, Adam et al. 2016. Realising consilience: How better communication between archeologists, historians and natural scientists can transform the study of past climate change in the Mediterranean. Quaternary Science Reviews (136): 5-22.

Koselleck, Reinhart 1977. Standortbindung und Zeitlichkeit. Ein Beitrag zur historiographischen Erschließung der geschichtlichen Welt. In: Ders., Wolfgang J. Mommsen und Jörn Rüsen (Hg.). Objektivität und Parteilichkeit. München: Deutscher Taschenbuch-Verlag: $17-46$.

Loveluck, Christopher P. et al. 2018. Alpine Ice-core Evidence for the Transformation of the European Monetary System, AD 640-670. Antiquity (92/366): 1571-1585.

Majer, Jiří 2000. Konjunkturen und Krisen im böhmischen Silberbergbau des Spätmittelalters und der Frühen Neuzeit. Zu ihren Ursachen und Folgen. In: Markus Denzel (Hg.). Konjunkturen im europäischen Bergbau in vorindustrieller Zeit: Festschrift für Ekkehard Westermann zum 60. Geburtstag. Stuttgart: Steiner: 73-83.

Mauelshagen, Franz 2009. Keine Geschichte ohne Menschen. Die Erneuerung der historischen Klimawirkungsforschung aus der Klimakatastrophe. In: André Kirchhofer, Daniel Krämer und Christoph Maria Merki (Hg.). Nachhaltige Geschichte. Festschrift für Christian Pfister. Zürich: Chronos Verlag: 169-193.

Mauelshagen, Franz 2010. Klimageschichte der Neuzeit. Darmstadt: WBG.

McCormick, Michael 2011. History's Changing Climate: Climate Science, Genomics, and the Emerging Consilient Approach to Interdisciplinary History. Journal of Interdisciplinary History (42/2): 251-273.

McCormick, Michael, Paul Edward Dutton und Pascal Bohleber 2007. Volcanoes and the Climate Forcing of Carolingian Europe, A. D. 750-950. Speculum (82): 865-895. 
McCormick, Michael et al. 2012. Climate Change during and after the Roman Empire: reconstructing the past from scientific and historical evidence. Journal of Interdisciplinary History (42): 169-220.

McNeill, John 2018. Epilogue. In: Sam White, Christian Pfister und Franz Mauelshagen (Hg.). The Palgrave Handbook of Climate History. London: Palgrave MacMillan: 635-641.

Molenda, Danuta 1976. Investments in Ore Mining in Poland from the 13th to the 17th Centuries. The Journal of European Economic History (5): 151-170.

More, Alexander F. et al. 2017. Next-generation Ice Core Technology Reveals true Minimum Natural Levels of Lead $(\mathrm{Pb})$ in the Atmosphere: Insights from the Black Death. GeoHealth (1/4): 211-219.

More, Alexander F. et al. 2018. The Role of Historical Context in Understanding Past Climate, Pollution and Health Data in Trans-disciplinary Studies: Reply to Comments on More. GeoHealth (2/5): 162-170.

Newfield, Timothy P. und Inga Labuhn 2017. Realizing Consilience in Studies of the PreInstrumental Climate and Pre-Laboratory Disease. Journal of Interdisciplinary History (48/2): 211-240.

Rotberg, Robert I. und Theodore K. Rabb (Hg.) 1981. Climate and History. Studies in Interdisciplinary History. Princeton, NJ: Princeton University Press.

Schenk, Gerrit Jasper 2014. Common Grounds in Early Modern Disaster Experiences? Some Remarks on New Trends in Historical Disaster Research as Part of Environmental History and Climate History. In: Martin Knoll und Reinhold Reith (Hg.). An Environmental History of the Early Modern Period. Experiments and Perspectives. Wien: Lit: 11-18.

Sigl, Michael et al. 2015. Timing and Climate Forcing of Volcanic Eruptions for the past 2,500 Years. Nature (523): 543-549.

Slingerland, Edward und Mark Collard (Hg.) 2012. Creating Consilience. Integrating the Sciences and the Humanities. Oxford und New York: Oxford University Press.

Tangheroni, Marco 1984. Produzione ed esportazione del piombo in Sardegna. Secoli XIII-XV. Prime ricerche. Ricerche storiche (14/1): 7-34.

Verna, Catherine 2001. Le Temps des Moulines. Fer, technique et societé dans les Pyrénées centrales (XIIIe-XVIe siècles). Paris: Publications de la Sorbonne.

Whewell, William 1840. The Philosophy of the Inductive Sciences: Founded upon Their History, 2 vols. London: John W. Parker.

White, Sam, Christian Pfister und Franz Mauelshagen (Hg.) 2018. The Palgrave Handbook of Climate History. London: Palgrave MacMillan.

Wilson, Edward O. 1998. Consilience. The Unity of Knowledge. New York: Knopf.

\section{Martin Bauch}

Leibniz-Institut für Geschichte und Kultur des östlichen Europa (GWZO) Abteilung „Mensch und Umwelt"

Reichsstraße 4-6

04109 Leipzig

martin.bauch@leibniz-gwzo.de 


\section{Potentiale und Kritik an der retrospektiven Diagnose in der Medizingeschichte}

Matthis Krischel

Im Januar 2019 fand in Düsseldorf eine Veranstaltung unter dem Titel „Babylon Berlin und Medizin: Gesundheit und Krankheit in der Zwischenkriegszeit" statt. Dabei wurde unter anderem über das in der ARD-Fernsehserie „Babylon Berlin“ thematisierte „Kriegszittern“ referiert, ein Phänomen, das bei vielen Soldaten des Ersten Weltkriegs auftrat und sich in unkontrolliertem Zittern der Gliedmaßen äußerte. In der Diskussion stellte das Publikum die Frage, welche Krankheit hinter dem Zittern der Kriegsheimkehrer stecken mochte: Waren die Ursachen etwa organische Verletzungen des Nervensystems oder posttraumatische Belastungsstörungen?

Hier wurde - unbewusst - die Frage nach einer retrospektiven Diagnose gestellt, der sich die anwesenden Medizinhistoriker*innen jedoch verweigerten. Jeder Krieg habe seine eigenen Krankheiten hervorgebracht, einschließlich des Vietnamkriegs- und Golfkriegssyndroms. Gehäuft bei Kriegsheimkehrern auftretende Kombinationen von Symptomen könnten dabei teils auf im jeweiligen Krieg eingesetzte Waffen und teils auf Umwelteinflüsse zurückgeführt werden, etwa Artillerie, Giftgas und Schützengräben im Ersten Weltkrieg.

Gleichzeitig müssen Gesundheit und Krankheit aber auch als soziale Konstrukte verstanden werden: Der zu Beginn des 20. Jahrhunderts formulierte Begriff der „Kriegsneurose“ nimmt Bezug auf den kurz vorher geprägten Begriff der „traumatischen Neurose“. Dieser wurde zunächst verwendet, um Nervenleiden nach Unfällen zu beschreiben, die zu keinen diagnostizierbaren organischen Verletzungen geführt hatten. Nach der Übernahme des Traumabegriffs aus der Chirurgie in die Nervenheilkunde wurde noch bis über das Ende des Erstens Weltkriegs hinaus die These des Berliner Neurologen Hermann Oppenheim diskutiert, ob die Symptome durch molekulare Veränderungen des Nervensystems oder rein psychisch hervorgerufen würden. Gleichzeitig hatte bereits der „traumatischen Neurose“ ein Ruch von Rentenbetrug angehaftet und sie war mit der Hysterie, einer weiblich konnotierten Nervenerkrankung, in Zusammenhang gebracht worden. Als im Laufe des Krieges immer mehr Soldaten als „Kriegszitterer“ die Front verließen, wurden diese Assoziationen auf die „Kriegsneurose“ übertragen (Thomann \& Rauschmann 2003). Dass aber nicht nur naturwissenschaftliche und medizinische Kriterien, „sondern bald mehr politische, weltanschauliche oder moralische Einstellungen“ (von Weizsäcker 1929) an der Definition der „traumatischen Neurose“ als Krankheit beteiligt waren, stell- 
te bereits 1929 der Arzt und medizinische Anthropologe Viktor von Weizsäcker fest. Diese Aspekte sind jeweils durch ein konkretes historisches, politisches und soziales Umfeld geprägt (Thomann \& Rauschmann 2003: 137).

Aus diesen Gründen ist es problematisch, die 1980 formulierte Diagnose „posttraumatische Belastungsstörung“ auf den Ersten Weltkrieg anzuwenden. Gleichzeitig ist die retrospektive Diagnose für einige Personen weiter attraktiv, lässt sie doch hoffen, historische Fragen auf der Basis des neuesten (heutigen) Standes der medizinischen Wissenschaft zu beantworten und so herauszufinden, „wie es eigentlich gewesen“ ist (Ranke).

Mit diesem Spannungsfeld zwischen Objektivierung von Gesundheit und Krankheit in der Geschichte und dem Versuch, sie als raum-, zeit- und kulturgebunden im Kontext ihrer Formulierung zu verstehen, beschäftigt sich dieser Beitrag. Er entsteht als Teil einer Debatte, die 2018 in NTM mit dem Forum Genetic History angestoßen wurde (NTM Redaktion 2018). Im Gegensatz zur „ancient DNA“ und der Sequenzierung des Erbguts von Populationen mit dem Ziel, Abstammung zu rekonstruieren, wird die retrospektive Diagnose in der Medizingeschichte schon länger thematisiert (Sandison 1967). Entsprechend sieht sich dieses Fach auch schon länger mit grundsätzlichen Fragen konfrontiert: Welchen Aussagewert haben die Ergebnisse moderner Methoden, die auf historische Quellen angewandt werden? Welchen Erkenntnisgewinn verspricht etwa die retrospektive Diagnose der Krankheit eines römischen Kaisers? Und wo macht sie es komplizierter, eine Krankheit und das Verhalten eines kranken Menschen in ihrem historischen und kulturellen Kontext zu verstehen? Im Folgenden soll die Debatte der letzten circa 20 Jahre knapp zusammengefasst werden. Einige der Argumentationsmuster der professionellen Medizingeschichte werden vielleicht auch in der Wissenschaftsgeschichte und im Schnittbereich zwischen Paläogenetik und Geschichtswissenschaft Anregungen liefern. Dabei geht es nicht darum, sich den neuen, naturwissenschaftlichen Methoden zu verschließen, sondern vielmehr kritisch zu reflektieren, wo ihre Grenzen liegen, wo sie helfen können, offene Fragen zu beantworten und wo sie neue Fragen aufwerfen.

Wolfgang Eckart und Robert Jütte beschreiben die retrospektive Diagnose als „verminte[s] Gelände“ (Eckart \& Jütte 2014: 365). Heute werden vor allem zwei Stoßrichtungen diskutiert: die Pathographie (Biographie von Personen mit Fokus auf ihre Krankheiten) und die Paläopathologie (Untersuchung menschlicher Überreste auf Krankheitsanzeichen). Die beiden Bereiche können sich überschneiden, etwa wenn paläopathologische Methoden angewendet werden, um die Krankheitsgeschichte einer bestimmten Person zu rekonstruieren. 


\section{Pathographie}

Am Beispiel von Pathographien des polnisch-französischen Komponisten Frédéric Chopin (1810-1849) zeigt Axel Karenberg Probleme der retrospektiven Diagnose auf (Karenberg 2009). Als grundsätzliches Problem versteht er, dass eine auf historischen Quellen basierende Diagnose zwar schlüssig sein kann, jedoch immer nur auf Beschreibungen von Symptomen beruht, die häufig aus nicht-medizinischen Kontexten stammen. Der Arzt könne den Patienten selber nicht untersuchen und auch objektivierende Verfahren, etwa Laboruntersuchungen, seien in der Regel nicht möglich. Somit bleibe die retrospektive Diagnose nicht falsifizierbar und letztlich reine Spekulation. Zudem erkennt Karenberg in den Krankheiten, die Chopin zugeschrieben wurden, klare Tendenzen: Zu Beginn des 20. Jahrhunderts wurden Tuberkulose, in den 1980er Jahren Mukoviszidose und zu unterschiedlichen Zeitpunkten verschiedene psychiatrische Erkrankungen „diagnostiziert“. Dabei sei auffällig, so Karenberg, dass jeweils Krankheiten mit tagesaktueller Relevanz auf den historischen Patienten zurückprojiziert wurden, ohne dabei die Wandelbarkeit und soziale Einbettung des medizinischen Wissens selbst zu reflektieren.

Karenberg spricht sich nicht pauschal gegen eine Erforschung der Krankheiten historischer Personen aus, fordert aber, diese als historische Interpretation anzulegen, die etwas über die medizinische Praxis und den sozialen Umgang mit Krankheit und kranken Menschen im Untersuchungszeitraum aussagt. Selbst wenn sich anhand eines paläopathologischen Labortests ein mit einer Krankheit assoziiertes genotypisches Merkmal erkennen lasse, würde dies nur begrenzt eine Aussage zur phänotypischen Ausprägung beim Patienten erlauben.

Noch deutlicher auf den Wandel der Nosologie, also die Beschreibung und systematische Einteilung von Krankheiten, geht Christoph auf der Horst am Beispiel der Syphilisdiagnosen des Schriftstellers Heinrich Heine (1797-1856) ein (auf der Horst 2004). Er zeigt, dass die Syphilis seit 1905 als durch das Bakterium Treponema pallidum verursachte Infektionskrankheit verstanden wird, während vorher astrologische Konstellationen, göttliche Strafe für moralische Verfehlungen oder ein humoralpathologisches „Verderben“ des Blutes als Auslöser der Krankheit betrachtet wurden. Auch konnte die Syphilis nicht systematisch von anderen sexuell übertragbaren Krankheiten unterschieden werden, die ebenso durch ein Einreiben mit Quecksilbersalbe behandelt wurden, etwa Gonorrhöe, Frambösie oder Ulcus molle. Der Begriff der Syphilis im vorbakteriologischen Zeitalter ist also im Kuhn'schen Sinne inkommensurabel mit dem Begriff im bakteriologischen Zeitalter. 
Zusätzlich weist auf der Horst auf weitere Herausforderungen hin, die sich aus der Mehrdeutigkeit von Begriffen im historischen Verlauf ergeben: Heine selbst hatte bei sich eine Tabes (Auszehrung) diagnostiziert. Erst nach Heines Tod wurde entdeckt, dass eine unbehandelte Syphilisinfektion nach Jahren bis Jahrzehnten zu einer Neurosyphilis führen kann, die sich in psychiatrischen Symptomen und progressiver Paralyse (fortschreitender Lähmung) manifestieren kann. Ein Ausfall von Funktionen des Rückenmarks wird dabei als Tabes dorsalis bezeichnet. Wenn unkritische Leser*innen nun Heines Selbstdiagnose der Tabes als Selbstdiagnose einer Neurosyphilis verstehen, so entgeht ihnen die Inkommensurabilität der beiden unterschiedlichen medizinischen Konzepte, die beide mit dem Begriff Tabes bezeichnet werden.

Chopin und Heine stehen hier stellvertretend für die Krankheitsgeschichten zahlloser "großer Männer" (und gelegentlich „großer Frauen“). In vielen Fällen liegt deren Leben noch deutlich weiter zurück und ist viel weniger umfassend dokumentiert, was die Diagnosestellung weiter in den Bereich des Spekulativen verschiebt. Im Fall der retrospektiven Diagnose von Schurken und Diktatoren besteht sogar die Gefahr, das Verhalten von Einzelnen oder Gruppen zu pathologisieren und so soziale, politische und kulturelle Gründe für ihr Handeln in den Hintergrund zu drängen.

Auf retrospektiver Diagnose basierende Pathographien werden von der Mehrheit der Medizinhistoriker*innen heute abgelehnt. Pointiert fordern Eckart und Jütte eine historisch-kritische Pathographie, die sich am theoretischen und praktischen Stand der Medizin sowie an Gesellschaft und Kultur der Zeit und des Ortes orientiert, von dem die Krankheitsbeschreibung stammt. So könne es nicht nur gelingen, „Kategorien des Erkennens, Denkens und Verstehens" aus der Perspektive der historischen Quelle zu verstehen, sondern durch Kontrastierung mit dem heutigen Krankheitsverständnis auch dieses als nicht wesensnotwendig zu erkennen (Eckart \& Jütte 2014: 365). Gleichzeitig wenden sich die beiden Autoren klar gegen eine „spekulative Diagnosestellung aus der Rückschau heraus, die heutige, ebenfalls dem Wandel unterliegende Kategorien zugrunde legt“. Diese verbiete sich ihrer Meinung nach und habe „in einer professionellen Medizingeschichte nichts zu suchen“ (Eckart \& Jütte 2014: 366 f.).

\section{Paläopathologie}

In einem Werk zur Geschichte der Infektionskrankheiten bezeichnet KarlHeinz Leven eine Sichtweise, die moderne Krankheitsentitäten in die Vergangenheit projiziert, als „medizinhistorisch wenig sinnvoll“ (Leven 1997: 
10). Nichtsdestotrotz erkennt er pathologische Befunde an Knochen und Gelenken aus dem alten Ägypten, der Antike und dem Mittelalter an, die mit heute bekannten Krankheiten in Verbindung gebracht werden. Insbesondere für Infektionskrankheiten sei jedoch die „Beziehung zwischen Wirtsorganismus und Krankheiterreger" von enormer Bedeutung, so dass die Krankheiten „bedingt durch genetische, ökologische, soziale und medizinische Faktoren [sich] in ihrem Erscheinungsbild, Schweregrad, in ihrer Verbreitung im Lauf der Zeit wandeln“ (Leven 1997: 14). Wenn beispielsweise ein Krankheitserreger in eine virgin population eingeschleppt werde, die ihm bisher nicht ausgesetzt war und deshalb keine Abwehrkräfte besitzt, könne es zu sehr schweren Krankheitsverläufen und schneller Verbreitung kommen. Als Beispiele führt Leven etwa die Masern und Pocken an, die in der frühen Neuzeit von Europa nach Amerika gebracht wurden.

An anderem Orte geht Leven auf innere und äußere Grenzen der Paläopathologie ein (Leven 1998). Unter inneren Grenzen versteht er die $\mathrm{Zu}$ verlässigkeit bzw. Fehleranfälligkeit der naturwissenschaftlichen Methoden. Naturgemäß könnten nur erhaltene Funde untersucht werden, die meist zufällig und selten repräsentativ seien. Während viele Krankheiten an den erhaltenen Überresten - meist Knochen - keine Zeichen hinterlassen, könnten durch Krankheiten veränderte Knochen „durch Umwelteinflüsse eher beeinträchtigt bzw. vernichtet werden als gesunde“ (Leven 1998: 176) oder zu beobachtende Knochenveränderungen nach dem Tod entstanden sein. Bei einer genetischen Analyse sei der Nachweis eines Erregers kein sicheres Indiz für eine Erkrankung, wenn eine spätere Besiedlung der Überreste bzw. eine Kontamination nicht ausgeschlossen werden kann. Und natürlich ist auch das naturwissenschaftliche Wissen selbst wandelbar. Grundsätzlich zu diesem Argument bemerkt Jörg Feuchter: „Das bedeutet nicht, dass die aktuelle genetisch-historische Wissensproduktion zur Vergangenheit nichts wert sei und nicht beachtet werden sollte. Aber sie bedarf der kritischen Distanz. Erst die Zukunft wird zeigen, welches Wissen sich endgültig bestätigt und welches nicht" (Feuchter 2016).

Am Beispiel der Lepra zeigt Leven eine Grenze zwischen Paläopathologie und Medizingeschichte auf. Der Nachweis typischer Knochenveränderungen bzw. von Mycobacterium leprae in antiken oder mittelalterlichen Überresten sei „nicht die Geschichte der Lepra, sondern ein Baustein dazu“ (Leven 1998: 177). Die vormoderne Krankheit Lepra oder Aussatz umfasste ein viel breiteres Spektrum von Hauterkrankungen als die moderne Lepra. Die vormoderne Krankheit hatte zahlreiche soziale, kulturelle, religiöse und medizinische Konnotationen, die sich an der damaligen zeitgenössischen Krankheitskonzeption und Diagnose orientierten. Somit sei eine Unterscheidung zwischen „echten“ und „unechten“ Fällen nach heutigem Wissensstand anachronistisch. 


\section{Fazit}

Die professionelle Medizingeschichte steht - das sollte deutlich geworden sein - der retrospektiven Diagnose kritisch gegenüber. Krankheiten werden heute zu einem wichtigen Anteil als sozial konstruiert verstanden, Konzepte von Gesundheit und Krankheit als kulturell und historisch wandelbar. Wenn wir etwa die Interpretation von Bakterien als Krankheitserreger als epistemische Dinge verstehen, die erst im Labor entstehen, dann wird deutlich, dass sie zum historischen Verständnis von Krankheit im vorbakteriologischen Zeitalter wenig beitragen. Dies gilt umso mehr, wenn Medizinhistoriker*innen nach dem individuellen Erleben von kranken Menschen, den Begründungsansätzen von Behandlern und den sozialen Zuschreibungen von Krankheit fragen.

Es mag gute naturwissenschaftliche oder medizinische Gründe geben, etwa den Erreger der „spanischen Grippe“ von $1918 \mathrm{zu}$ isolieren und sein Genom zu sequenzieren, für genuin medizinhistorische Fragen bleibt dies aber bestenfalls ein Baustein. Hier stehen „die Umstände der Krankheit, das jeweilige Verständnis von ihr sowie ihre gesellschaftlichen Auswirkungen“ (Fangerau 2010) im Vordergrund des Erkenntnisinteresses. Ein paläopathologischer Befund allein ist keine Antwort auf eine historische Fragestellung, sondern ist für Medizinhistoriker*innen eine weitere Quelle, die der Interpretation bedarf. Im besten Fall kann die neue Quelle zu neuen Fragestellungen führen oder funktioniert als Hypothesengenerator für die Forschung (Feuchter 2016). Hier hat die in der Medizingeschichte bereits breit diskutierte retrospektive Diagnose viel mit der modernen aDNA-Forschung gemein.

\section{Literatur}

Eckart, Wolfgang und Robert Jütte 2014. Medizingeschichte. Eine Einführung. 2., überabeitete und ergänzte Auflage. Köln: Böhlau.

Fangerau, Heiner 2010. Zu Paläopathologie und Geschichte der Medizin. Das Beispiel der Influenzapandemie. Urologe (49/11): 1406-1410.

Feuchter, Jörg 2016. Über die Herausforderung der Geschichtswissenschaft durch die Genetik: Zwölf Thesen zur „Genetic History“. URL: https://mittelalter.hypotheses.org/7629, zuletzt aufgerufen am 15.04.2019.

Horst, Christoph auf der 2004. Historisch-kritische Pathographien und Historizität: Eine kritische Auswertung der Heine-Pathographien am Beispiel der Syphilisdiagnosen Heinrich Heines. In: Alfons Labisch und Norbert Paul (Hg.) Historizität. Erfahrung und Handeln - Geschichte und Medizin. Stuttgart: Steiner: 121-152.

Karenberg, Axel 2009. Retrospective Diagnosis: Use and Abuse in Medical Historiography. Prague Medical Report (110/2): 140-145. 
Leven, Karl-Heinz 1997. Die Geschichte der Infektionskrankheiten von der Antike bis ins 20. Jahrhundert. Landsberg: ecomed.

Leven, Karl-Heinz 1998. Krankheiten: Historische Deutung versus retrospektive Diagnose. In: Norbert Paul und Thomas Schlich (Hg.) Medizingeschichte: Aufgaben, Probleme, Perspektiven. Frankfurt: Campus: 153-185.

NTM-Redaktion 2018. Forum: Genetic History. NTM (26/3): 301-350.

Sandison, A. 1967. Sir Marc Armand Ruffer (1859-1917) Pioneer of Palaeopathology. Medical History (11/2): 150-156.

Thomann, Klaus-Dieter und Michael Rauschmann 2003. Die „posttraumatische Belastungsstörung“ - historische Aspekte einer „modernen“ psychischen Erkrankung im deutschen Sprachraum. Medizinhistorisches Journal (38): 103-138.

Weizsäcker, Viktor von 1929. Über Rechtsneurosen. Nervenarzt (2): 569-581.

\section{Matthis Krischel}

Institut für Geschichte, Theorie und Ethik der Medizin

Medizinische Fakultät

Heinrich-Heine-Universität Düsseldorf

Universitätsstraße 1

40225 Düsseldorf

matthis.krischel@hhu.de

Hinweis des Verlags Der Verlag bleibt in Hinblick auf geografische Zuordnungen und Gebietsbezeichnungen in veröffentlichten Karten und Institutsadressen neutral. 